\title{
Forecasts and assimilation experiments of the Antarctic ozone hole 2008
}

\author{
J. Flemming ${ }^{1}$, A. Inness ${ }^{1}$, L. Jones ${ }^{1}$, H. J. Eskes ${ }^{2}$, V. Huijnen ${ }^{2}$, M. G. Schultz ${ }^{3}$, O. Stein ${ }^{3}$, D. Cariolle ${ }^{4,5}$, D. Kinnison ${ }^{6}$, \\ and G. Brasseur ${ }^{6}$ \\ ${ }^{1}$ European Centre for Medium-Range Weather Forecasts, Reading, UK \\ ${ }^{2}$ Royal Dutch Meteorological Institute, De Bilt, The Netherlands \\ ${ }^{3}$ Research Center Jülich, IEK-8: Troposphere, Jülich, Germany \\ ${ }^{4}$ Météo-France, Toulouse, France \\ ${ }^{5}$ Centre Européen de Recherche et de Formation Avancée en Calcul Scientifique, Toulouse, CNRS URA 1875, France \\ ${ }^{6}$ National Centre for Atmospheric Research, Boulder, Colorado, USA
}

Received: 4 February 2010 - Published in Atmos. Chem. Phys. Discuss.: 9 April 2010

Revised: 15 February 2011 - Accepted: 18 February 2011 - Published: 3 March 2011

\begin{abstract}
The 2008 Antarctic ozone hole was one of the largest and most long-lived in recent years. Predictions of the ozone hole were made in near-real time (NRT) and hindcast mode with the Integrated Forecast System (IFS) of the European Centre for Medium-Range Weather Forecasts (ECMWF). The forecasts were carried out both with and without assimilation of satellite observations from multiple instruments to provide more realistic initial conditions. Three different chemistry schemes were applied for the description of stratospheric ozone chemistry: (i) a linearization of the ozone chemistry, (ii) the stratospheric chemical mechanism of the Model of Ozone and Related Chemical Tracers, version 3, (MOZART-3) and (iii) the relaxation to climatology as implemented in the Transport Model, version 5, (TM5). The IFS uses the latter two schemes by means of a two-way coupled system. Without assimilation, the forecasts showed model-specific shortcomings in predicting start time, extent and duration of the ozone hole. The assimilation of satellite observations from the Microwave Limb Sounder (MLS), the Ozone Monitoring Instrument (OMI), the Solar Backscattering Ultraviolet radiometer (SBUV-2) and the SCanning Imaging Absorption spectroMeter for Atmospheric CartograpHY (SCIAMACHY) led to a significant improvement of the forecasts when compared with total columns and vertical profiles from ozone sondes. The combined assimilation of observations from multiple instruments helped to overcome limitations of the ultraviolet (UV) sen-
\end{abstract}

Correspondence to: J. Flemming (johannes.flemming@ecmwf.int) sors at low solar elevation over Antarctica. The assimilation of data from MLS was crucial to obtain a good agreement with the observed ozone profiles both in the polar stratosphere and troposphere. The ozone analyses by the three model configurations were very similar despite the different underlying chemistry schemes. Using ozone analyses as initial conditions had a very beneficial but variable effect on the predictability of the ozone hole over 15 days. The initialized forecasts with the MOZART-3 chemistry produced the best predictions of the increasing ozone hole whereas the linear scheme showed the best results during the ozonehole closure.

\section{Introduction}

The paper presents forecasts of the ozone hole over Antarctica in 2008, which were made with and without assimilation of ozone retrieval products from multiple sensors to provide ozone initial conditions, and which used different chemistry schemes of varying complexity.

The ozone hole in 2008 was large and long-lasting. Its size at the beginning of October was larger than $90 \%$ of the events since 1979 (WMO, 2008). The stratospheric ozone layer over Antarctica has shown severe catalytic ozone destruction in austral spring since the late 1970s and similar phenomena are observed over the Arctic (WMO/UNEP, 2007). Reductions in chlorofluorocarbon emissions imposed by the Montreal protocol and its amendments are predicted to lead to a recovery of springtime stratospheric ozone over the poles, but it will take several decades before the ozone layer will

Published by Copernicus Publications on behalf of the European Geosciences Union. 
be healed (Newman et al., 2006). Hence, monitoring of the stratospheric ozone depletion remains important to assess the increase in UV radiation at the surface.

Ultraviolet to visible range (UV-VIS) instruments provide the longest record of ozone measured from space, and sensors such as the Ozone Monitoring Instrument (OMI) and the SCanning Imaging Absorption spectroMeter for Atmospheric CartograpHY (SCIAMACHY) can provide high resolution ozone total column observations. However, the restricted sun light at the ozone-hole onset limits the use of UV-VIS sensors at this time. The Microwave Limb Sounder (MLS) does not depend on sun light and can make profile observations over Antarctica during the whole year, albeit with a low horizontal resolution. Modelling the correct timing and magnitude of the Antarctic ozone hole involves a complex interplay between dynamical phenomena, i.e. the strength and temperature of the Antarctic vortex, slow heterogeneous chemical processes during the austral winter and the rapid release of chlorine and bromine when sun light reaches the polar region (Solomon, 1999).

Ozone has been included in global numerical weather prediction (NWP) models as a prognostic variable since the mid1990's (Derber and Wu, 1998) in order to assimilate satellite observations of ozone within the NWP data assimilation framework. Besides the monitoring of the man-made ozone depletion, the crucial role of ozone in the atmospheric radiation budget and its link to wind fields (Allaart et al., 1993; Riishojgaard, 1996) through its tracer characteristics motivated the introduction of the ozone variable. The underlying ozone chemistry schemes are often simplifications of stratospheric processes derived from parameterizations of Chemical Transport Model (CTM) results (Cariolle and Déqué, 1986; McLinden et al., 2000; McCormack et al., 2006) or observed climatologies (Fortuin and Kelder, 1998). For example, Geer at al. (2007) compare different ozone assimilation systems based on linear chemistry schemes. Coy et al. (2007) investigate the influence of observation and model biases for the assimilation by a model system with and without a linear chemical scheme. As pointed out in a review by Lahoz et al. (2007), using data assimilation systems based on CTMs (e.g. Khattatov et al., 2000; Ménard et al., 2000; Errera et al., 2008; Massart et al., 2009) has been an alternative to the NWP approach. The CTM systems can apply more complex chemical schemes and give the opportunity to study the chemical impact on other species during the ozone assimilation.

At the European Centre for Medium-Range Weather Forecasts (ECMWF), ozone has been operationally assimilated and forecast using an updated version of the linearized scheme by Cariolle and Déqué (1986) since 1999 (Hólm et al., 1999), and it was included in the ERA40 re-analysis (Dethof and Hólm, 2004). Within the "Global and regional Earth-system Monitoring using Satellite and in-situ data" (GEMS) project (Hollingsworth et al., 2008), the ECMWF's integrated forecast system (IFS) was extended to be able to simulate and assimilate, using its 4D-Var implementation, reactive gases such as ozone, carbon monoxide, nitrogen dioxide, formaldehyde and sulfur dioxide in both the troposphere and the stratosphere. This has been achieved by means of a coupled system (Flemming et al., 2009) in which the IFS is linked to the CTMs MOZART-3 (Horowitz et al., 2003; Kinnison et al., 2007) or TM5 (version KNMI-cy3-GEMS, Krol et al., 2005). In the coupled system IFS-CTM, the IFS makes use of the simulation of chemistry, emission and deposition in the CTM without directly simulating these source and sink processes in the IFS. The MOZART-3 chemical mechanism explicitly simulates ozone chemistry including stratospheric processes whereas the TM5 version used here applies a relaxation to stratospheric ozone climatology. The new coupled system combines the NWP approach with the CTM-based approach for simulation and assimilation of atmospheric constituents in both the stratosphere and the troposphere. It is therefore essential that the ozone assimilation by the coupled system IFS-CTM does not degrade the ozone values in the troposphere. This is a difficult task because of the dominance of stratospheric ozone in the total column and the limited vertical information of satellite observations.

Ozone retrievals from OMI, SCIAMACHY, SBUV-2 and MLS have been assimilated in this study. The MLS retrievals have the potential of being important for the quality of the ozone analyses because of the ability of MLS to measure during the polar night and to provide vertical profile information between the lower mesosphere and the stratosphere. While many studies (e.g. Levelt, et al., 1998; Eskes et al., 2002; Geer et al., 2006) focus on the assimilation of only one specific instrument, ozone profile retrievals from MLS have been assimilated together with retrievals from one UVinstrument such as SBUV-2 (Jackson and Orsolini, 2008) or OMI (Stajner et al., 2008). The use of multiple instruments raises the question of the inter-instrument biases since they could degrade the analyses. The precise quantification of these biases in the time of the ozone hole, as shown in this paper, is complicated by the different sampling of the instruments, the reduced retrieval quality at low solar elevation and the pronounced horizontal ozone gradients.

In addition to evaluating the quality of the ozone assimilation and chemistry, this paper also investigates the time span over which the initialization with ozone analyses improves the forecast for each chemical scheme. This "chemical predictability" of ozone has to be distinguished from the "meteorological predictability" of the underlying dynamical processes. In order to demonstrate the impact of the chemical scheme on the predictability, initialized ozone forecast were carried out with all three chemistry schemes and with a tracer without chemical conversion.

Predictability is understood as the time span over which a satisfactory forecast can be made. The predictability is therefore related to the model performance, which depends on the quality of the model, its initial conditions and boundary data (Kalnay, 2003). The chaotic behavior of atmospheric 
dynamics has led to the well known realization that the predictability of the weather itself is limited (see for an overview Lorenz, 2006, in Palmer and Hagedorn, 2006) and that it varies with respect to the meteorological situation. The impact of the chaotic aspect of the predictability can be quantified with an ensemble of meteorological forecasts which use slightly different meteorological initial conditions. These forecasts will diverge more quickly if the predictability is low. The sensitivity of CTMs to initial conditions of the concentrations is strongly controlled by the strength of the simulated sink and source terms. As in the case of the meteorological model, the impact of the initial conditions vanishes but - in contrast to the meteorological case - an ensemble of CTM forecasts will not diverge if the initial concentration of the concentrations were slightly disturbed but they will reach a state controlled by the sources and sinks.

The chemical lifetime of ozone in the stratosphere varies with height from a month in the lower part to a couple of hours in the upper part as simulated by two-dimensional CTMs (e.g., Fig. 6 in Gray and Pyle, 1989). The lifetime of ozone is also significantly shorter during the development of the ozone hole.

Most of the variability of stratospheric ozone on the global scale is caused by dynamical processes. That is why anomalies of the geopotential height in the stratosphere have been successfully used as a predictor for the ozone variability (Long et al., 1996). Sekiyama and Shibata (2005) identify the predictability of the $100 \mathrm{hPa}$ geopotential height as the limiting factor for the predictability of the ozone anomalies. Simmons et al. (2005) show that the dynamical features of the vortex, even during the vortex split event in 2002, can be well predicted. The quality of the ozone hole forecast will depend strongly on the correct representation of the chemical processes since the ozone lifetime is shortened.

Eskes et al. (2002) obtain a predictability range of at least four to five days based on anomaly correlations of total ozone with respect to monthly means for the southern hemisphere. Stajner et al. (2006) show improvements in prediction of ozone in middle latitudes over several days from wellcaptured dynamical variability and improved initialization of ozone values in the polar vortex due to assimilation of ozone data from solar occultation instruments. Tegtmeier and Shepherd (2007) report much longer lasting, i.e. half a year and more, correlations of observed stratospheric ozone anomalies in the extra-tropics, which they attribute to anomalies in odd nitrogen compounds.

While the dynamical processes determine the spatial patterns of the ozone fields, the biases of the simulated ozone concentrations are caused by the accumulation of chemical biases and of biases due to errors in the resolved-scale and sub-scale transport processes (van Noije et al., 2004; Rind et al., 2007). If these biases are corrected by using ozone analyses as initial conditions, the effect might be longlasting because of the long-lasting impact of ozone anomalies mentioned above. The correct initialization of stratospheric ozone fields is therefore not only important for NRT forecasts but also for independent CTM runs, which are shorter than one year.

Using prognostic ozone fields in the radiative transfer calculation is an interesting prospect to improve temperature biases of NWP or climate models in particular in the stratosphere. For this purpose, simulations of realistic ozone profiles are required. For instance, de Grandpré et al. (2009) show improvements in temperature predictability at $50 \mathrm{hPa}$ by one day with a coupled Chemistry-Dynamics Assimilation system, which uses a full chemistry scheme and assimilates ozone profiles of the Michelson Interferometer for Passive Atmospheric Sounding (MIPAS).

The remainder of the paper is structured as follows. The three different chemistry schemes and the model configuration are described in Sect. 2. The data assimilation set-up and the assimilated observations, including an investigation of the inter-instrument biases, are also introduced in this section. Section 3 contains the evaluation of the ozone forecast with and without ozone assimilation in the period from August to December 2008. The first step is the validation against column values of ozone sondes to evaluate the analyses with independent data. In the next step, the ozone-hole size below 220 Dobson Units (DU) is used as a compact parameter to study the forecasts with different forecast lead times and initializations. The last step in the evaluation looks at the shape of the forecast ozone profiles. The paper ends with conclusions and a summary of the results in Sect. 4.

\section{Model and experiment set-up}

\subsection{Three schemes for stratospheric ozone chemistry}

The model configurations of the IFS for this study differed only in their simulation of the ozone chemistry. The IFS used (i) a linearized scheme, which is a further development of the scheme by Cariolle and Déqué (1986), (ii) a full chemistry scheme implemented in the CTM MOZART-3 and (iii) a climatological approach, which is the relaxation to the ozone climatology as implemented in the CTM TM5. The latter two schemes have been made accessible to the IFS by means of a two-way coupled system that links the IFS to the CTMs MOZART-3 and TM5. The coupled system is described and validated in Flemming et al. (2009). The coupled CTMs, which are driven by IFS meteorological data, provide the IFS with the tendencies of sink and source processes which are not directly modeled in the IFS. The chemical conversion rates from the linear scheme are calculated as part of the IFS code. 


\subsubsection{Linear scheme (IFS)}

The parameterization is a description of the ozone chemistry in the stratosphere. The temporal change due to chemical sources and sinks of ozone is simulated in the following way:

$$
\frac{d \mathrm{O}_{3}}{d t}=c_{1}+c_{2}\left(\mathrm{O}_{3}-\overline{\mathrm{O}_{3}}\right)+c_{3}(T-\bar{T})+c_{4}\left(\int_{p}^{0} \mathrm{O}_{3}-\int_{p}^{0} \overline{\mathrm{O}_{3}}\right)+c_{5}\left(\overline{\mathrm{Cl}_{\mathrm{eq}}}\right)^{2} \mathrm{O}_{3}
$$

The change depends on the deviations of the ozone concentration $\mathrm{O}_{3}$, temperature $T$ and overhead ozone columns $\int_{p}^{0} \mathrm{O}_{3}$ from the respective mean modeled 2-D photochemical equilibrium state $\bar{T}$ and $\overline{\mathrm{O}_{3}}$ (Cariolle and Teyssèdre, 2007, version 2a). The coefficients $c_{1}, c_{2}, c_{3}$ and $c_{4}$ vary monthly and are given for different latitude band and pressure levels. The formula also includes a parameterization of the rapid ozone loss due to the chlorine catalytic cycle which is based on a prescribed global equivalent chlorine content $\overline{\mathrm{Cl}_{\mathrm{eq}}}$ of $3.31 \mathrm{ppbv}$. The coefficient $c_{5}$ is not zero only at temperatures below $195 \mathrm{~K}$ in daylight conditions. Its non-zero value corresponds to an e-folding time of about 5 days.

\subsubsection{Full scheme (IFS-MOZART)}

The MOZART-3 chemical mechanism simulates the tropospheric and stratospheric chemistry with 106 species. The chemical mechanism is described in Kinnison et al. (2007). It also includes the ozone destruction caused by catalytic chemistry of halogenic compounds and their activation by heterogeneous reaction on the surfaces of polar stratospheric clouds (PSC). The PSCs simulated by the MOZART-3 are liquid binary sulfate, nitric acid trihydrate (NAT), supercooled ternary solution and water ice. The model version described in Kinnison et al. (2007) was further updated in the following details: (i) improved local conservation of inorganic chlorine and bromine, (ii) correction of photolysis look-up tables, (iii) update of rate constants according to Sander et al., (2006) and (iv) improved simulation of surface area density of NAT and ice PSCs. The MOZART-3 code version 3.5.02 used in this study is consistent with the code of the Whole Atmosphere Community Climate Model (WACCM), version 3.5.48, which was validated in SPARC CCMVal (2010).

\subsubsection{Climatological scheme (IFS-TM5)}

TM5 simulates tropospheric ozone with a modified CBM4 (Carbon Bond Mechanism 4) scheme (Houweling et al., 1989). It does not apply any representation of stratospheric chemistry; instead the ozone field in the stratosphere is constrained by climatology. This is based on a monthly varying, pressure dependent, zonal-average ozone concentration field representative for the years 1980-1991 (Fortuin and Kelder, 1998). Ozone is nudged to the climatology above $45 \mathrm{hPa}$ in the tropics, and above $90 \mathrm{hPa}$ at all other latitudes. The relax- ation times are 2.5 and 4 days, for the tropics and the extratropics, respectively.

\subsection{Data assimilation method}

The ozone satellite observations were assimilated by ECMWF's incremental formulation of the four-dimensional variational data assimilation (4D-Var) method. A description of the 4D-Var data assimilation algorithm of the IFS is given by Mahfouf and Rabier (2000) and with focus on the assimilation of aerosol in Benedetti et al. (2009). In 4D-Var, a cost function is minimized over a time window in such a way that the resulting analysis is an optimal combination of the model fields and the observations. Prescribed model and observation error statistics determine how much weight is given to the modeled and observed values in the combination. 4D-Var makes it possible to fully take into account all observations within the minimization time window. In 3D-Var, unlike 4DVar, observations are assumed to occur at the same time.

A detailed description and examples of the application of the coupled system IFS-MOZART for the assimilation of atmospheric constituents can be found in Inness et al. (2009). The implementation of the chemistry simulation into the 4DVar apparatus with the coupled system follows the assimilation of ozone with the parameterized chemistry (Dethof and Hólm, 2004), which means that the chemistry scheme is applied to determine the increments between the model and the observations but it is not included in the minimization by the adjoint and tangent linear model which is applied to these increments. The adjoint and tangent linear model accounts only for transport processes, which are assumed to be the main reason for the variability on the time scale of the assimilation window of twelve hours.

The background errors of ozone were derived from an ensemble of forecasts (Fisher and Andersson, 2001) applying the linear ozone chemistry scheme. The background error matrix is represented in a wavelet formulation (Fischer, 2006). The same background error matrix was used in all assimilation runs.

The assimilation of ozone data with all three model configurations is statistically univariate in the sense that zero background error covariance terms between the chemical tracers and the meteorological fields were defined. The impact of the ozone data assimilation on wind and temperature fields has been switched off. A possible impact on the rest of the chemical species in MOZART-3's full chemistry scheme appeared only as a consequence of the chemical interaction in the coupled CTM, which uses the analyzed ozone fields as initial conditions every $12 \mathrm{~h}$ (Flemming et al., 2009).

\subsection{Assimilated satellite observations}

Table 1 lists the assimilated satellite observations. OMI and SCIAMACHY retrievals are total column data whereas MLS and SBUV-2 retrievals are partial columns at mostly 
Table 1. Assimilated satellite observations, specifications and blacklist criteria with respect to solar elevation (SOE) and latitude (LAT).

\begin{tabular}{llllll}
\hline Sensor & Platform & Assimilated columns & $\begin{array}{l}\text { Blacklist cri- } \\
\text { teria }\end{array}$ & Provider & Product \\
\hline SBUV-2 & NOAA 16/17/18 & $6(0.1-1013 \mathrm{hPa})$ & $\begin{array}{l}\text { SOE }<6^{\circ} \\
\text { LAT }<-80^{\circ}\end{array}$ & NOAA & V8 \\
OMI & AURA & Total & SOE $<10^{\circ}$ & NASA & OMDOAO3 v883 \\
SCIAMACHY & Envisat & Total & SOE $<6^{\circ}$ & KNMI & O3doas \\
MLS & AURA & $16(0.02-215 \mathrm{hPa})$ & & NASA & MLS-Aura_L2GP-O3_v02-23-NRT-03 \\
\hline
\end{tabular}

stratospheric levels. Comprehensive validation studies of the retrieval with ground based measurements were presented by Balis et al. (2007) for OMI, Froidevaux et al. (2008) for MLS, by Eskes et al. (2005) for SCIAMACHY and Bhartia et al. (1996) for SBUV-2.

The horizontal resolution of MLS is about $200-300 \mathrm{~km}$ and the vertical resolution is about $3 \mathrm{~km}$ in the range from $0.1 \mathrm{hPa}$ to $215 \mathrm{hPa}$. The horizontal resolution of OMI is 13 $x 24 \mathrm{~km}$ and that of SCIAMACHY is $30 \times 60 \mathrm{~km}$. The horizontal resolution of MLS is about 2-3 times coarser than the resolution of the assimilating model. The horizontal resolution of OMI and SCIMACHY is about 8 and 3 times finer than the IFS resolution of about $120 \mathrm{~km}$

The vertical resolution of MLS in the considered region was about half as fine as the resolution of the assimilating model. The height of the IFS layers varies from $1 \mathrm{~km}$ to $2 \mathrm{~km}$ between 150 and $1 \mathrm{hPa}$, whereas the MLS data have a vertical resolution of about $3 \mathrm{~km}$ in this pressure range. It was therefore useful to provide the data assimilation system with partial columns to better account for the difference in vertical resolution. The MLS data were converted to partial columns without loss of the vertical resolution.

The data providers observation-error data were used, but they were modified to be at least $10 \%$ for OMI and SBUV. The original retrieval errors were increased because they did not include the representativeness error of the observation for the respective model grid box. In the considered area between $60^{\circ}$ and $90^{\circ} \mathrm{S}$, the errors of OMI and SCIAMACHY ranged from $20 \%$ to $30 \%$. The error of the stratospheric partial columns was about $5-10 \%$ above $68 \mathrm{hPa}$ for MLS and above $16 \mathrm{hPa}$ for SBUV-2, and up to $25 \%$ for the partial columns below.

As part of ECMWF operational activities, the ozone observations are monitored in terms of inter-instrument biases and their impact on the analysis before they are actively used in operational mode (Dragani, 2009). This procedure results in a quality control that prevents observations from being assimilated if their accuracy is low. Blacklist criteria have been developed to exclude data observed at low solar elevation angles (see Table 1). Further, the high-resolution data from OMI and SCIAMACHY are thinned by choosing one observation within each $1^{\circ} \times 1^{\circ}$ grid box. The thinning algorithm takes the first observation which is not closer than

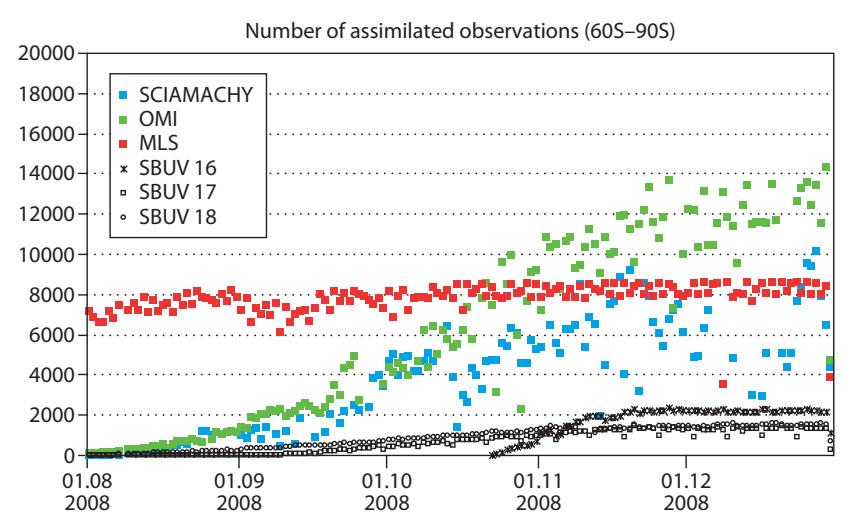

Fig. 1. Number of assimilated satellite observations per day over Antarctica $\left(60^{\circ} \mathrm{S}-90^{\circ} \mathrm{S}\right)$ in the period from 1 August to 31 December 2008 .

half a thinning-grid box length from the selected observation in neighboring grid boxes. A different observation is chosen for different times because of the variable mapping between the model grid and the orbit location. Thinning is applied to minimize the spatial correlation between the observation errors, which is not accounted for within the 4D-Var implementation.

Figure 1 shows the number of the assimilated observations, i.e. the ones passing the quality test, for the period 1 August to 31 December 2008 between $60^{\circ}-90^{\circ} \mathrm{S}$. The sensors using solar UV-VIS radiation (SCIAMACHY, OMI, and SBUV) were only gradually providing more usable observations with increasing length of the solar day. The microwave observations of MLS were available in the same quantity over the whole period and were therefore the dominant information source until mid-October. The number of the SBUV2 observations was small compared to that of the other instruments, which led to their generally small influence during the assimilation. SBUV-2 had the biggest influence in the upper stratosphere. All observations apart from MLS were received in NRT and the hindcast experiments used also these data sets.

The study of inter-instrument biases has to consider that the instruments measure at different times and locations, which is of importance because of the large horizontal 
Table 2. List of experiments.

\begin{tabular}{|c|c|c|c|c|c|}
\hline Experiment Label & Ozone initial conditions & Assimilated Sensors & Chemistry scheme & FC Length hours & NRT \\
\hline IFS-MOZ-FC & Forecast & - & Full & 96 & Yes \\
\hline IFS-MOZ-ANA* & Analysis & SCIA, SBUV-2, OMI & Full & 72 & Yes \\
\hline IFS-MOZ-ANA & Analysis & SCIA, SBUV-2, OMI, MLS & Full & 72 & - \\
\hline IFS-MOZ-FC15 & $\begin{array}{l}\text { Forecast, } 1 \text { st and } 16 \text { th day } \\
\text { each month analysis }\end{array}$ & SCIA, SBUV-2, OMI, MLS & Full & 24 & - \\
\hline IFS-TM5-FC & Forecast & - & Climatology & 24 & - \\
\hline IFS-TM5-ANA & Analysis & SCIA, SBUV-2, OMI, MLS & Climatology & 72 & - \\
\hline IFS-TM5-FC15 & $\begin{array}{l}\text { Forecast, } 1 \text { st and } 16 \text { th day } \\
\text { each month analysis }\end{array}$ & SCIA, SBUV-2, OMI, MLS & Climatology & 24 & - \\
\hline IFS-FC & Forecast & - & Linear & 24 & - \\
\hline IFS-ANA & Analysis & SCIA, SBUV-2, OMI, MLS & Linear & 72 & - \\
\hline IFS-FC15 & $\begin{array}{l}\text { Forecast, } 1 \text { st and } 16 \text { th day } \\
\text { each month analysis }\end{array}$ & - & Linear & 24 & - \\
\hline TRC-FC15 & $\begin{array}{l}\text { Forecast, } 1 \text { st and } 16 \text { th day } \\
\text { each month analysis }\end{array}$ & - & none & 24 & - \\
\hline
\end{tabular}

gradients during the ozone-hole period. Figure 2 shows time series of the 24 -hourly spatial averages over $60^{\circ}-90^{\circ} \mathrm{S}$ of the assimilated total column observations from OMI and SCIAMACHY and the sum of the partial columns from MLS and SBUV-2. The typical values of the MLS partial columns in the lowest 10 levels, i.e. between 215 and $5 \mathrm{hPa}$, was about $15 \mathrm{DU}$ per level and about $2 \mathrm{DU}$ in the levels above. The lowest SBUV-2 partial column, i.e. below $16 \mathrm{hPa}$, contained about $75 \%$ of the total column, and most of the remaining ozone mass was part of the column above, i.e. between 6 and $16 \mathrm{hPa}$. The data sets from all instruments showed the same overall temporal variation but with large biases until the end of October. The MLS added columns were lower than the UV sensors by about $50 \mathrm{DU}$ until this point in time. About half of this difference was caused by the fact that MLS observed the area poleward to $82^{\circ} \mathrm{S}$ all the time. It was therefore able to capture a larger proportion of the ozone hole. The missing tropospheric contribution, i.e. below $215 \mathrm{hPa}$, in partial columns in the MLS data (see Table 1) contributed about 18-22 DU. The UV-VIS sensors showed a considerable spread until the end of October. This variability seemed also be largely caused by the different locations of the assimilated observations. This is supported by the fact that a 12-hourly accumulation of the observations, i.e. at the length of the assimilation window and not over the whole day, led to a diurnal variation of up to $50 \mathrm{DU}$, which was caused by the zonal asymmetry of ozone hole. The high values from SBUV-2 on NOAA-16 in the second half of October have been identified as a sensor fault.

More detailed insight into the inter-instrument biases can be obtained from comparing the departures of the observations from a three-dimensional ozone field. By doing so the observed partial column values can better be compared with observed total column values at different locations. Figure 3 shows the frequency distribution of the analysis departures

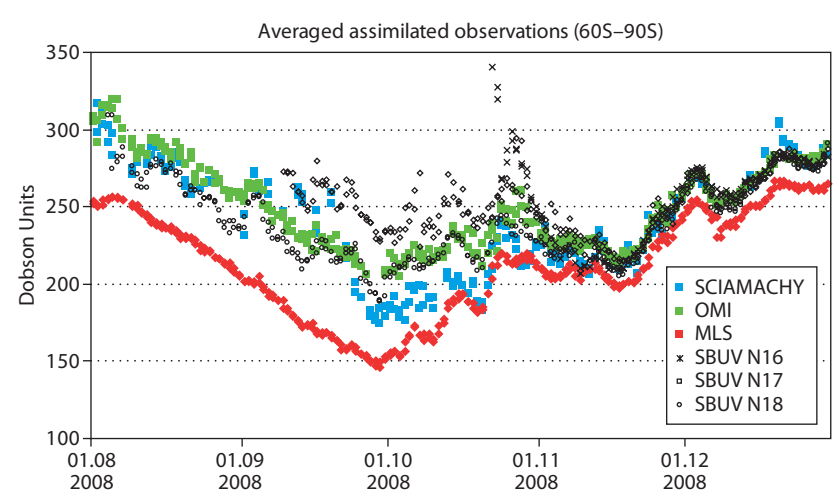

Fig. 2. Daily mean of assimilated ozone total columns in DU from SCIAMACHY and OMI and sum of partial columns from MLS and SBUV-2 aboard NOAA 16, 17 and 18 in averaged over Antarctica $\left(60^{\circ} \mathrm{S}-90^{\circ} \mathrm{S}\right)$ in the period from 1 of August to 31 of December 2008 .

of IFS-MOZART for OMI, SCIAMACHY and MLS against latitude, averaged over one week at the end of August and the end of November. The analysis departures from the 16 partial MLS columns between 0.02 and $215 \mathrm{hPa}$ (see Table 1) were symmetric and had nearly zero average at all latitudes between $60^{\circ} \mathrm{S}-90^{\circ} \mathrm{S}$ for all levels as a whole (see Fig. 3) and also for the individual levels (not shown). This means that the analysis was bias-free against this data set, which covered the stratosphere only, both at the end of August and November. At the end of August, OMI's total column values had a bias of about 4 DU against the analysis with the highest bias occurring at lower solar elevation (not shown). The SCIAMACHY total columns were on average bias free but showed small negative biases at higher solar elevation at the end of August. Many more observations from OMI and SCIAMACHY had been assimilated at the end of November. At this time the 

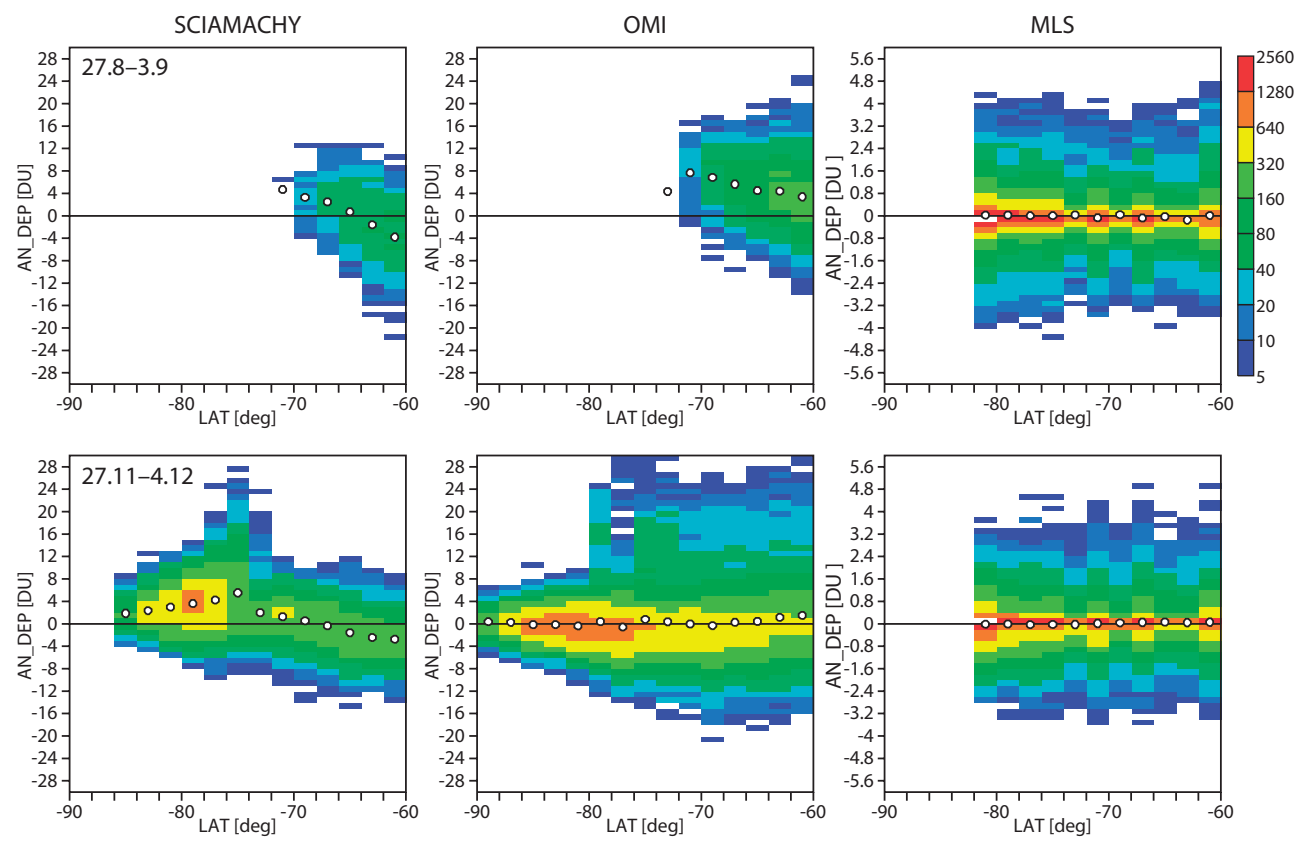

Fig. 3. Frequency distribution of analysis departures (observation minus analysis) from IFS-MOZ-ANA (see table 2) in DU (vertical axis) against latitude (horizontal axis) for total column observations from SCIAMACHY (left) and OMI (middle) and partial columns observations from MLS (right, different y-axis range) over Antarctica $\left(60^{\circ} \mathrm{S}-90^{\circ} \mathrm{S}\right)$ in the period from 27 August to 3 September 2008 (top) and from 27 November to 4 December 2008 (bottom). The circles show the average for each latitude interval.

OMI total columns were almost bias-free against the analysis and therefore also against MLS. The SCIAMACHY values had a mostly positive bias against the analysis of about $4 \mathrm{DU}$ when averaged over the whole domain. When binned according to solar elevation (not shown), the SCIAMACHY bias was highest at low solar elevation where it reached an average value of $12 \mathrm{DU}$. The lowest SBUV-2 columns, i.e. below $16 \mathrm{hPa}$, had an overall negative bias of about $2 \mathrm{DU}$ at the end of November. SBUV-2 on NOAA 18 showed increasing negative biases from 4 to $8 \mathrm{DU}$ at between $74^{\circ}$ and $82^{\circ} \mathrm{S}$.

Figure 3 also shows the latitude range for which satellites observations were assimilated. While MLS always covered the area polewards to $82^{\circ} \mathrm{S}$, OMI and SCIAMACHY observations had not been used south of about $70^{\circ} \mathrm{S}$ by the end of August. By the end of November observations over the whole domain were assimilated.

In summary, the biases between the instruments varied in time, reached values of up to $3 \%$ and were highest at low solar elevation.

\subsection{Experiment set-up}

The IFS forecasts evaluated in this paper (Table 2) differed in the model set-up, i.e. the choice of the applied chemical scheme, and whether ozone analyses were used to initiate the forecast. The forecasts were started at 00:00 UTC every day in the period from 1 August to 31 December 2008. The me- teorological initial conditions for each forecast were derived from the operational ECMWF analysis. The ozone initial conditions were taken either from the previous forecast (FC) or from an assimilation experiment which produced analyses at 00:00 and 12:00 UTC in two $12 \mathrm{~h}$ 4D-Var cycles every day for the initialized forecasts (ANA) . This assimilation experiment also used the operational analysis as meteorological initial conditions.

The assimilation experiments were run for each model setup, i.e. each chemical scheme, and the analyses were used for the forecast with the respective scheme. The assimilation experiments used observations from SCIAMACHY, SBUV2, OMI and MLS. Additionally, the NRT forecast by IFSMOZART (IFS-MOZ-ANA*), for which MLS data were not available, was evaluated.

To further study the influence of the chemical scheme on the forecast quality, additional one-day forecasts (FC15) were carried out which were initialized from the previous forecast as the FC runs on all days apart from the 1st and 16th day of each month, for which they were initialized by the respective ozone analysis. FC15 runs were also carried for a tracer without chemical conversion.

The IFS was run with a T159 spectral resolution and the grid point space was represented by a reduced Gaussian grid (Hortal and Simmons, 1991), which has a grid box size of about $125 \mathrm{~km}$. The vertical discretization consisted of 60 hybrid sigma-pressure levels, reaching up to $0.1 \mathrm{hPa}$. The CTMs MOZART-3 and TM5 were run in the coupled 
Table 3. Ozone sondes used for the evaluation.

\begin{tabular}{lrrrrrrll}
\hline Name & Lat & Lon & \multicolumn{8}{l}{ Observations per month in 2008 } & Network/Institute \\
\hline & & & Aug & Sep & Oct & Nov & Dec ll & \\
Neumayer & $-70.65^{\circ}$ & $-8.26^{\circ}$ & 7 & 13 & 10 & 7 & 4 & WOUDC \& NDACC/AWI-NM \\
McMurdo & $-77.85^{\circ}$ & $166.67^{\circ}$ & 0 & 8 & 10 & 0 & 0 & NDACC/University of Wyoming \\
Marambio & $-64.24^{\circ}$ & $56.63^{\circ}$ & 9 & 8 & 9 & 9 & 9 & WOUDC/FMI-SMNA \\
Syowa & $-69.0^{\circ}$ & $39.6^{\circ}$ & 6 & 5 & 4 & 5 & 5 & WOUDC/JMA \\
Ushuaia & $-54.85^{\circ}$ & $68.31^{\circ}$ & 2 & 4 & 6 & 5 & 1 & WOUDC/SMNA \\
Macquari Island & $-54.5^{\circ}$ & $158.94^{\circ}$ & 4 & 4 & 2 & 0 & 0 & WOUDC/ABM \\
South Pole & $-90.0^{\circ}$ & & 6 & 11 & 9 & 6 & 5 & NDACC/NOAA \\
\hline
\end{tabular}

Table 4. Average of ozone columns in DU derived from sondes (OBS) and biases (model minus observation) for all model configurations and stations (see Table 3).

\begin{tabular}{lrrrrrrr}
\hline Station & OBS & IFS-MOZ-FC & IFS-TM5-FC & IFS-FC & IFS-MOZ-ANA & IFS-TM5-ANA & IFS-ANA \\
\hline Neumayer & 159.8 & 28.7 & 40.1 & -3.1 & 5.0 & 7.7 & 8.4 \\
Syowa & 185.3 & 22.9 & 35.5 & -4.7 & 3.6 & 8.1 & 3.7 \\
McMurdo & 155.3 & 35.3 & 42.2 & 5.5 & 10.7 & 11.5 & 11.0 \\
Marambio & 206.6 & 23.7 & 40.4 & -15.0 & 13.0 & 12.3 & 12.1 \\
Ushuaia & 217.4 & 11.5 & 25.4 & -22.3 & 9.0 & 10.5 & 12.1 \\
Macquarie Island & 304.8 & 6.4 & 33.3 & -19.3 & 4.7 & 9.2 & 8.4 \\
South Pole & 154.3 & 13.9 & 30.2 & -3.7 & 3.2 & 3.7 & 6.5 \\
\hline
\end{tabular}

experiments on a regular latitude-longitude grid of $1.9^{\circ} \times 1.9^{\circ}$ and $2^{\circ} \times 3^{\circ}$ grid box length respectively; they used the same vertical discretization as the IFS.

\section{Evaluation of the forecasts}

\subsection{Synoptic overview}

The 2008 ozone hole started to grow rapidly after midAugust, which is about 2-3 weeks later than the average start time of the last ten years. It reached its maximum in midSeptember, being at this time only slightly smaller than the biggest recorded ozone hole in 2007. The 2008 ozone hole lasted longer than most previous events and ended in December. Its size in mid-October was larger than $90 \%$ of the years since 1979 according to WMO (2008). Van Peet et al. (2009) present GOME-2 profile retrievals from September to December 2008, which agreed well with sonde profiles from Neumayer station (see Table 3).

The temperature at $50 \mathrm{hPa}$ was below the 1979-2007 average on most days from June to August. The volume below the threshold temperature for the formation of PSCs type I (NAT) was well above the long-term average, in particular in early September. The vortex was stable and mostly concentric (WMO, 2008). A comprehensive evaluation of the meteorological forecasts and analyses is beyond the scope of this paper. Exemplarily, Fig. 4 shows time series of the monthly mean observed temperatures and the respective forecast er-
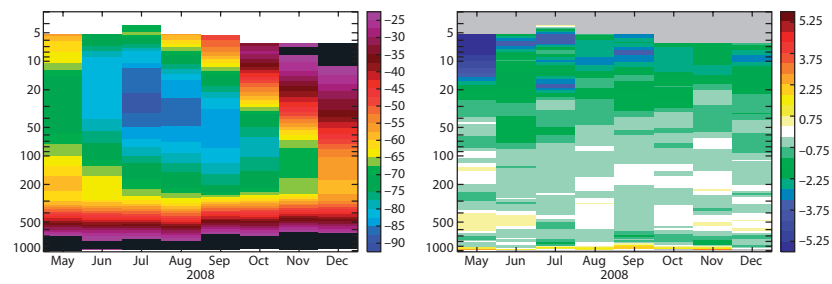

Fig. 4. Monthly mean of observed temperature profiles (left, in ${ }^{\circ} \mathrm{C}$, $\mathrm{y}$-axis pressure in $\mathrm{hPa}$ ) and respective forecast errors (right, in $\mathrm{K}$ ) over Neumayer station for the period from May to December 2008. Blue colours indicate low values and red colour high values.

rors at Neumayer Station from May to December 2008. The temperatures below the minus $85^{\circ} \mathrm{C}$ threshold of the formation of ice clouds (PSC type II) occurred in July and August. The forecast temperature profiles were very similar to the observed patterns in the region of the ozone hole between 150 $20 \mathrm{hPa}$, but they were about $0.5-1 \mathrm{~K}$ cooler than the observed values below $20 \mathrm{hPa}$ and about $2-3 \mathrm{~K}$ cooler above $20 \mathrm{hPa}$, in particular in July.

Humidity observations from sondes are less reliable in the stratosphere and are therefore not suited for a test of the forecast humidity. MLS retrievals of water vapor can be used to evaluate the stratospheric humidity for latitudes up to $82^{\circ} \mathrm{S}$. The observation error varies from $15 \%$ at $100 \mathrm{hPa}$ to $4 \%$ at $1 \mathrm{hPa}$. (http://mls.jpl.nasa.gov/products/h2o_product.php). At the time of the PSC formation, the MLS water vapor retrievals had values of 2.5-3 ppmv within the polar vortex and 

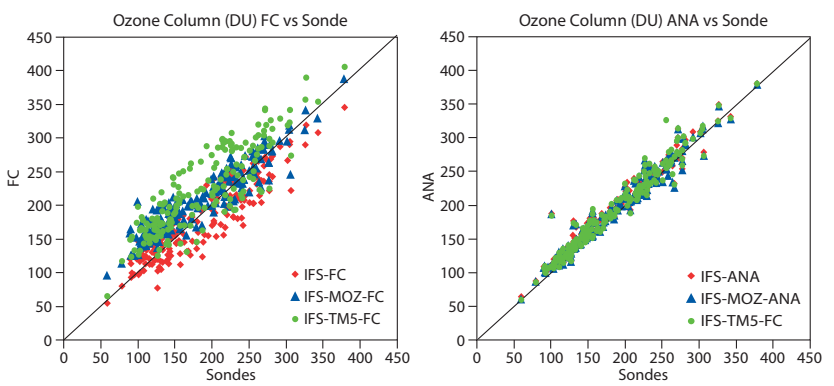

Fig. 5. Columns of ozone soundings at different locations (OBS, see Table 3) in the period from 1 August to 31st of December 2008 and the corresponding predictions for the first forecast day by IFSMOZART (blue triangle), IFS-TM5 (green circle) and IFS (red diamond) without assimilation (FC, left) and with assimilation (ANA, right).

4-5 ppmv outside the polar vortex at $56 \mathrm{hPa}$. PSCs were simulated within the polar vortex despite an underestimation of humidity by 1 ppmv inside the polar vortex. Outside the polar vortex the water vapor was $0.5-1$ ppmv below the MLS observations.

\subsection{Comparison with ozone columns from sondes}

The forecasts were evaluated against ozone soundings from seven locations (see Table 3) in the Antarctic region for the period August to December 2008. Typical uncertainties for these ozone observations in the lower stratosphere are less than $5 \%$ for both the random and the systematic error (e.g. Beekmann et al., 1994). The number of soundings varied for the different stations. Most observations were available in September and October when the ozone hole was fully developed. Marambio, Neumayer and South Pole station had the most complete records.

The observed ozone profiles were converted to ozone columns. The soundings stopped mostly at heights between 10 to $5 \mathrm{hPa}$ and the recorded top height was also applied in the calculation of the forecast ozone columns. The total column values, i.e. up to the model top of $0.1 \mathrm{hPa}$, were about 5\% larger than these vertically limited values. Figure 5 shows scatter plots of observed and forecast ozone columns by the three model systems with and without assimilation. Although there was a correlation of $0.93,0.87$ and 0.91 between the observations and the FC runs by IFS-MOZART, IFS-TM5 and IFS respectively, IFS-MOZART and IFS-TM5 mostly over-predicted whereas IFS under-predicted the observations. The largest relative biases for IFS-MOZART occurred at stations close to the edges of the ozone hole such as McMurdo and Neumayer, but McMurdo's bias was further increased by the observations coverage limited to September and October (see Table 3). Lower biases occurred at South Pole and at the stations mostly outside the ozone hole, where IFS showed in general the highest biases. When initialized with analyses, forecasts (ANA) improved to a large extent

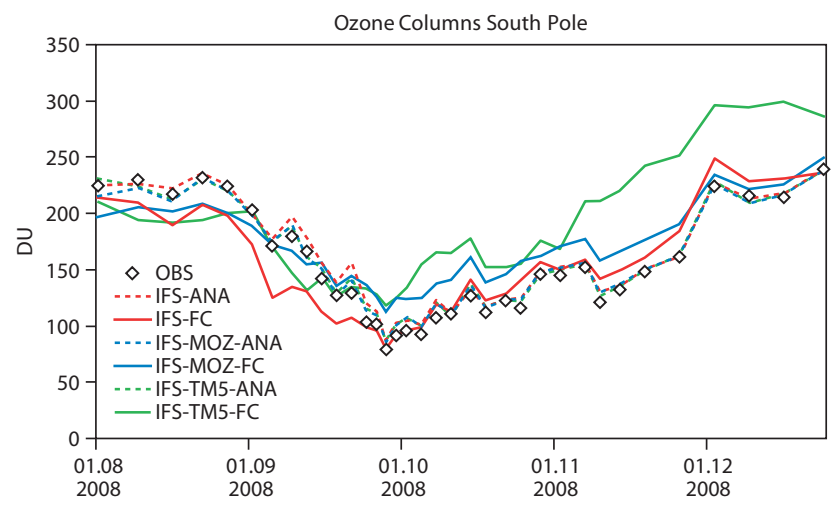

Fig. 6. Time series of observed total columns (OBS) in DU, y-axis, from ozone sondes at South Pole Station and from forecasts without (FC) and with assimilation (ANA) by IFS-MOZRT, IFS-TM5 and IFS. Only soundings whose top pressure was between 5 and $8.5 \mathrm{hPa}$ are shown.

(see Fig. 5). On the first forecast day, the mean biases of the IFS-MOZART, IFS-TM5 and IFS FC run were changed from 21.7, 36.1 and -8.2 DU to 7.3, 9.9 and 9.7 DU respectively by the initialization with the analyses. As described later, the low overall biases of IFS FC, which were even lower than the biases of IFS ANA, were caused by the compensation of underestimation in August and September and overestimation in the later months. IFS-ANA had a constant small positive bias over the whole period. Table 4 lists the biases and the observed averages for the individual stations. The ANA runs had the lowest biases at South Pole station; the highest biases occurred at Marambio, which is located closer to the edge of the ozone hole. The initialization with analyses improved not only the biases but also reduced the standard deviation of the errors from 24.7, 32.0 and 26.1 DU to 13.3, 13.9 and 13.5 DU for IFS-MOZART, IFS-TM5 and IFS respectively. The variation among the three different chemistry schemes was greatly reduced, which means that the analyses were mainly determined by the continuous assimilation of satellite observations rather than the underlying model approach. Figure 6 shows time series of the observations, the FC and ANA runs by all three model set-ups for South Pole station. The ANA runs followed the observations closely, whereas the biases of the FC runs varied in time, which will be discussed in the next section.

\subsection{Forecast of the development of the ozone hole size}

The size of the ozone hole forecast by the ANA, FC and FC15 runs after $12 \mathrm{~h}$ using the different chemistry schemes is shown as a function of time in Fig. 7. The ozone hole was expressed as the area fraction below 220 DU between $62^{\circ} \mathrm{S}$ and $90^{\circ} \mathrm{S}$. A discussion of the usefulness of this frequently used diagnostic threshold is given in Newman et al. (2004). Figure 8 contains maps of the ozone total column fields by the different forecasts for the 30 September 2008. 

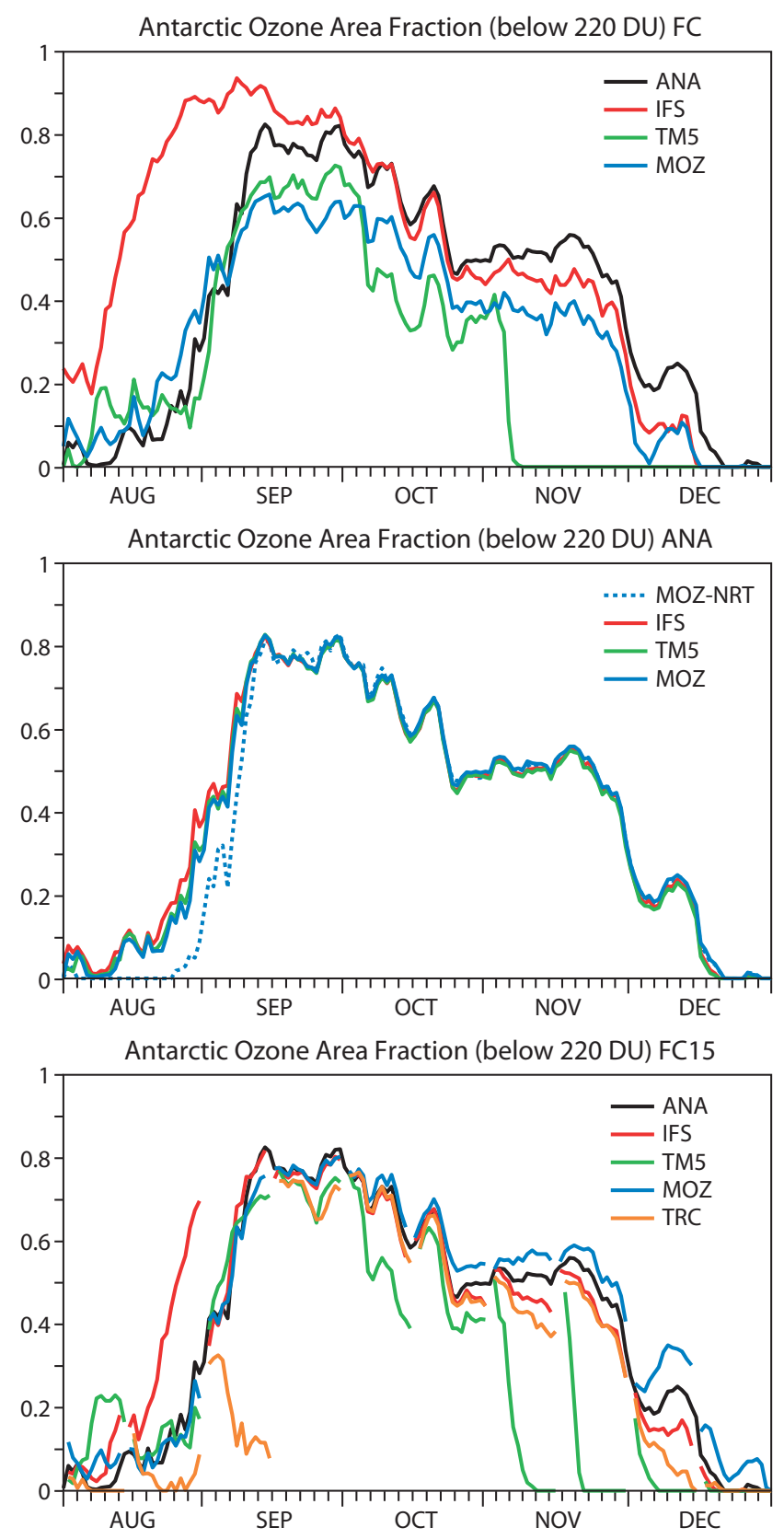

Fig. 7. Area fraction below $220 \mathrm{DU}$ in the area $62^{\circ} \mathrm{S}-90^{\circ} \mathrm{S}$ at 12:00 UTC from the runs without assimilation (FC, top), runs with assimilation (ANA, middle) and the runs initialized only on the 1 st and 16th day of each month (FC15, bottom) by IFS-MOZART (MOZ, blue), IFS (red), IFS-TM5 (green) and a tracer without chemistry (TRC, orange, FC15 only). See Table 1 for the assimilated satellite observations. MLS was not assimilated in the NRT ANA* run with IFS-MOZART (MOZ-NRT, dotted blue line, middle panel only).
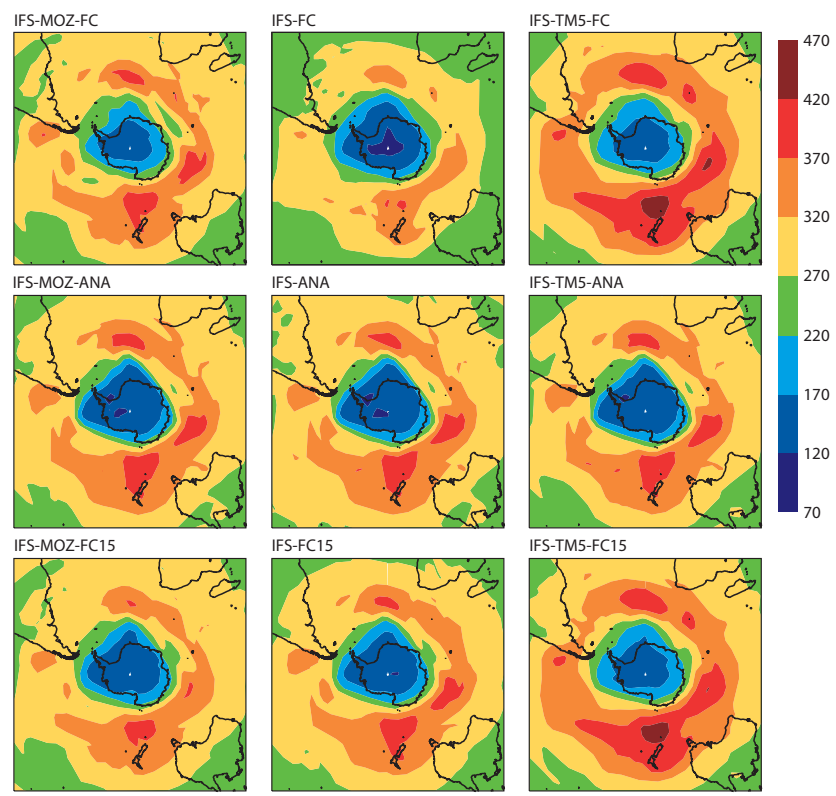

Fig. 8. Ozone total columns (DU) over Antarctica on 30 September 2008, 12:00 UTC, from the runs without assimilation (FC, top), with assimilation (ANA, middle) and from runs initialized 14 days previously (FC15, bottom) by IFS-MOZART, by IFS and by IFSTM5. Blue colours indicate low values below $220 \mathrm{DU}$; red and dark red colors indicate values above 370 DU.

The FC runs by IFS-MOZART correctly predicted the time of the ozone-hole development and its closure but it under-predicted the maximum extent by about $20 \%$ (Fig. 7 , top). The simulations of the ozone hole were an improvement over the simulations of the year 2000 ozone hole with MOZART-3 by Kinnison et al. (2007). Their simulated ozone hole is too small and delayed and the ozone values around the polar vortex are too high in early spring when using meteorological analyses from the ECMWF's operational system or a $4 \mathrm{D}-\mathrm{VAR}$ version of the re-analysis system as meteorological input data. Kinnison et al. (2007) conclude that an overestimation of the Brewer-Dobsen circulation (van Noije et al., 2004), which they also find in an underestimation of age-of-air, and enhanced mixing into the vortex are the reasons of the underestimation of their ozone hole. Monge-Sanz et al. (2007) had already reported that the transition from 3D-Var to 4D-Var improved the realism of the age-of-air simulation. O. Stein (personal communication) demonstrated that age-of-air was more realistic with the meteorological analyses of the 4D-VAR system used in this study than the ones used by Kinnison et al. (2007). The IFS-MOZART simulation in this paper showed more realistic ozone total columns fields around and inside the vortex (see Fig. 8, top) with the updated version of the IFS meteorological model. There were still deficiencies in the simulation of the vertical profiles, which will be discussed in Sect. 3.4.

The linearized scheme (IFS) forecast (FC) the ozone-hole development three weeks too early but the slow closure from 
October onwards followed the analyses very well. The exaggerated ozone loss by the linear scheme could be caused by the negative temperature bias of the analysis as shown in Fig. 4. Further, the temperature-triggered catalytic ozone loss term (see Sect. 2.1) does not take into account the delay between the conditioning of the PSCs and the activation of the chlorine. Cariolle and Teyssèdre (2007) show that the linear scheme, of which we used version $2 \mathrm{a}$, is able to produce an ozone hole with minimum values of $140 \mathrm{DU}$, which is about 20 DU higher than the observations from the TOMS instrument for the year 2001. A cold tracer (Cariolle and Teyssèdre, 2007, Eskes et al., 2003) may help to improve the simulation of the ozone-hole start with the linear scheme.

The climatological approach (IFS-TM5, FC) correctly predicted the quick development of the ozone hole but its full extent in September was slightly under-predicted. The forecast ozone hole had already disappeared by the start of November, when still half of the area south of $62^{\circ}$ had total ozone columns below $220 \mathrm{DU}$ in the analyses.

Despite the biases of the FC runs, the spatial patterns of the ozone total column fields were in all cases similar to the ANA and FC15 runs (e.g. see Fig. 8). Since the ANA run showed a very good agreement with observations, it can be concluded that the more dynamically driven exchange between the vortex and its surroundings was well represented by the transport scheme in the IFS.

It is apparent from Fig. 7 (middle) that the analyzed ozone total columns fields produced by the three different modeling approaches were very similar because the respective ANA runs did not differ to a large extent for day one. The largest differences, although only around 20DU, appeared in the vortex centre in August and September (Fig. 6), which is less observable at this time by the UV-based sensors OMI, SCIAMACHY and SBUV. These differences can be attributed to the differences in the chemistry schemes. When no MLS retrievals were available, as in the IFS-MOZ-ANA* run, the observed information content was further reduced in the area of the ozone hole (see Fig. 1), which led to an underestimation of the ozone hole by IFS-MOZ-ANA* in August and September (Fig. 7, middle).

\subsection{Impact of ozone initialization on the forecasts}

More insight into the impact of the chemical schemes on the predictability of the ozone hole can be obtained from the evaluation of the FC15 runs. The FC15 runs are equivalent to a sequel of ten 15-day model runs, which are started from an ozone analysis on the 1st and 16th day of each month.

Figure 7 (bottom) shows the predictions of the ozone-hole extent by each chemistry scheme and by the tracer without chemistry (TRC-FC15) as well as the respective values of the analysis. The importance of the chemistry in the period from mid-August to mid-September was demonstrated by the large deviation of the TRC-FC15 run from the analyzed values. The initialization with analyses on the $16 \mathrm{Au}-$
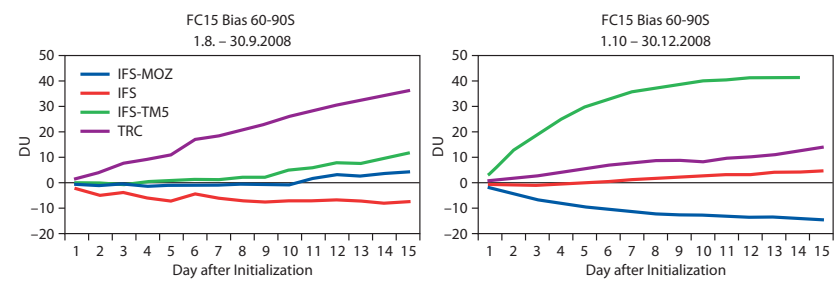

Fig. 9. Bias of the ozone total columns over $60-90^{\circ} \mathrm{S}$ from the FC15 runs with IFS-MOZART (blue), IFS (red), IFS-TM5 (green) and a tracer without chemistry (TRC, purple) for the period of the ozone hole development (left: 1 August-30 September, average of four FC15 runs) and its closure (right: 1 October-31 December, average of six FC 15 runs). The FC15 runs were initialized with ozone analyses at the forecast start.

gust could not fully correct the untimely simulation of the ozone hole with IFS. The initialization on 1 September led to a very realistic simulation of the ozone-hole size over the following 15 days by all schemes. In particular the IFSMOZART forecasts were very close to the analyses in this period. Around 16 September the ozone hole had reached its maximum size. The correction by initialization on this day was hardly needed by all schemes including the tracer to correctly forecast the mostly dynamically driven changes until the end of October. In the later stages of the ozone-hole closure chemical processes become more important since the TRC-FC15 runs diverged from the analyses. IFS-MOZART tended to predict a slightly delayed closure of the ozone hole whereas the linear IFS scheme slightly overestimated the ozone-hole closure. The overall correct forecast of the ozone hole suggests that the transport of ozone into the vortex was correctly simulated.

The closure of the ozone hole by IFS-TM5 was, as in the case of the FC run, enforced much too early, in particular in November and December. A test with no relaxation below $5 \mathrm{hPa}$ improved the simulation results of IFS-TM5-FC15 during the time of the ozone-hole closure at the expense of poorer results during the rapid development of the ozone hole, which could not be simulated correctly anymore.

Because the predictability differed between the time of the ozone-hole development and its closure, Fig. 9 shows the development of the bias in total columns over Antarctica for the periods 1 August to 30 September 2008 and 1 October31 December 2008. The results from the FC15 tracer runs helped to quantify the importance of the chemical sources and sinks at the time scale of the forecast length. The bias of FC15 TRC increased to about 35 DU over 15 days averaged over the first period. The full chemistry of IFS-MOZART was able to produce nearly unbiased forecasts of the rapid ozone-hole development up to 10 days. Negative and positive biases of about $+/-10$ DU occurred in the FC15 forecast with IFS and IFS-TM5 respectively after 15 days. During the second period, i.e. time of the ozone-hole closure, the FC15 tracer forecast had a positive bias of about $15 \mathrm{DU}$ after 

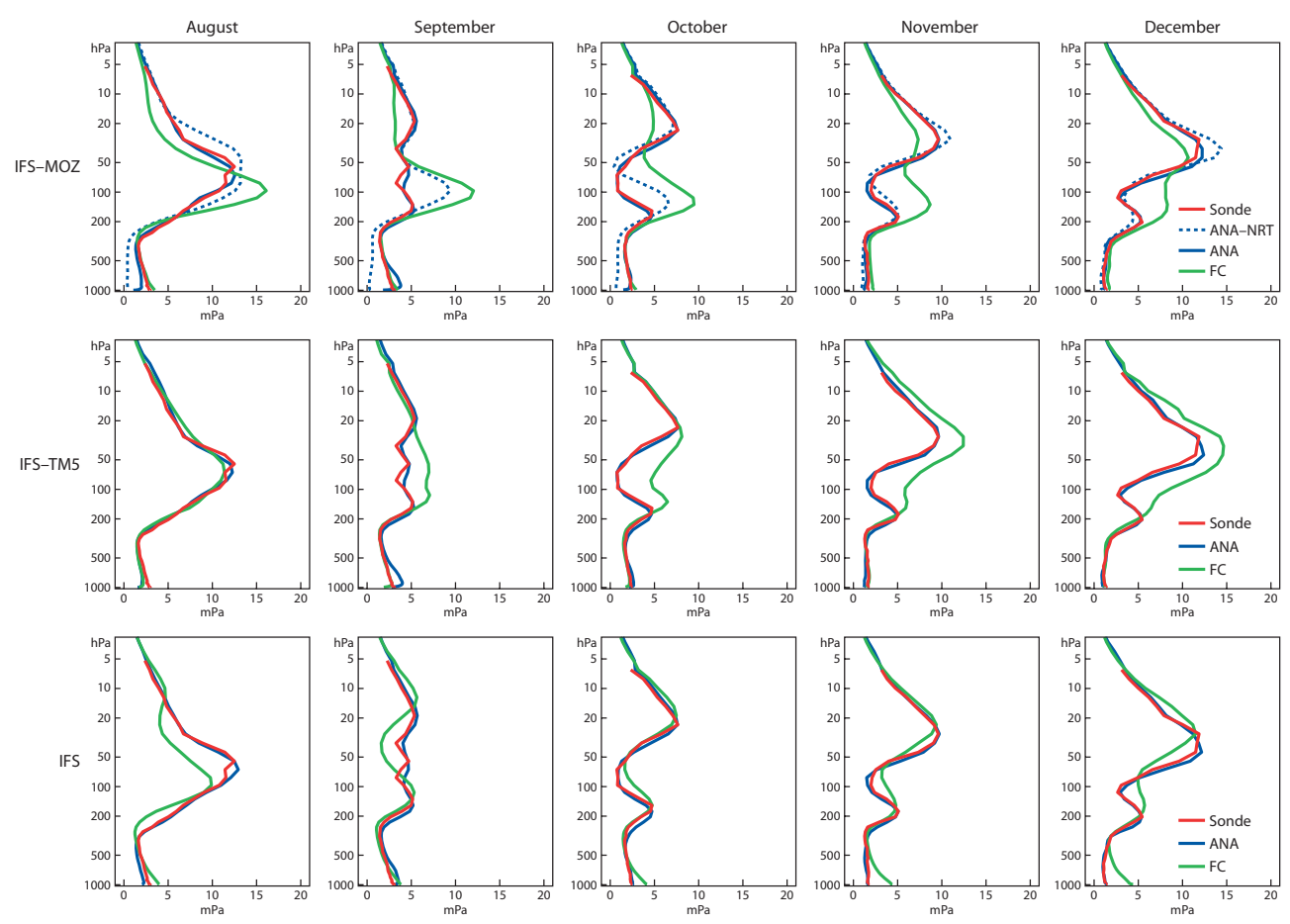

Fig. 10. Monthly averaged ozone profiles (partial pressure in $\mathrm{mPa}$ ) forecast by IFS-MOZART (top), by IFS-TM5 (middle) and by IFS (bottom) without assimilation (FC, green), with assimilation (ANA, blue), with assimilation but excluding MLS data (ANA*, blue dotted line, IFS-MOZART only), and observations (Sonde, red) at Neumayer Station from August to December 2008.

15 days. This would mean an overestimation of the ozone transport into Antarctica, if the chemistry was not important. The linear scheme, however, produced a smaller bias of about 5 DU showing the best predictability of the schemes during the ozone-hole closure. The full scheme of IFS-MOZART underestimated the ozone increase at a rate of about one DU per day. The large biases of IFS-TM5 showed the strong limitation of the climatological approach for forecast applications.

A bigger difference in the decrease of the ozone hole occurred in the FC15 runs started at 1 December (see Fig. 7, bottom). The IFS-MOZART run showed the development of a rather large scale negative bias of the ozone total columns which covered southern mid- and high latitudes. The difference between the values in and outside the vortex were correctly reproduced. The TRC run, i.e. without chemistry, showed a large positive bias in the vortex centre, indicating the importance of the ongoing ozone depletion, and a small negative bias in the mid-latitudes, which might be caused by insufficient ozone production. The linear scheme underestimated the ozone loss in the vortex but showed more correct values outside the vortex.

As a test of the importance of the meteorological forecast error, a sequence of initialized forecasts over 15 days with IFS, i.e. without the daily update of the meteorological initial conditions, was carried out. Its results did not significantly differ from the IFS-FC15 runs, which means that the large scale development of the polar vortex was correctly predicted by the IFS over 15 days. More dynamically complex events such as the vortex split in 2002 have a shorter meteorological predictability of about one week (Simmons et al., 2005).

\subsection{Evaluation of vertical profiles}

The assimilated satellite ozone retrievals (see Table 1) contained either no (OMI, SCIAMACHY and SBUV-2) or only limited information (MLS) about the shape of the ozone profile. Hence, ozone analyses with realistic total column values may not necessarily be in good agreement with the observed ozone profiles.

For the sake of brevity, only the match with observations from the soundings at Neumayer Station (see Table 3) is discussed in this section but the findings were also true for the other locations. Figure 10 shows monthly averages of observed and forecast (day one of FC and ANA) profiles from the three model configurations. The ozone hole became visible in the observed September average in the altitude range between 150 to $20 \mathrm{hPa}$; and it was largest in October.

The FC runs by the climatological scheme of IFS-TM5 correctly reproduced the height of the maxima and minima but underestimated the ozone loss from September onwards in the region above $200 \mathrm{hPa}$. The linear scheme of IFS produced the most realistic stratospheric monthly-averaged profiles after September but it overestimated the tropospheric 
values below $500 \mathrm{hPa}$ and under-estimated the stratospheric concentrations in August and September.

Without assimilation, the profiles of the run with IFSMOZART showed the indented shape typical for the ozone hole too late. The ozone depletion was too weak and occurred at a higher level than the observations suggest. The maximum ozone loss was simulated at a pressure range above $50 \mathrm{hPa}$ whereas the observations showed a stronger ozone decrease between $50-150 \mathrm{hPa}$. The identified cold bias above $50 \mathrm{hPa}$ (see Fig. 4) could be a reason for an overestimation of the ozone depletion by IFS-MOZART in this region. The same feature, i.e. the overestimated ozone loss above $50 \mathrm{hPa}$, was also found in the simulation with the linear scheme. The linear scheme responds directly to deviations from the climatological temperature field (see Sect. 2.1.). The lack of sufficient ozone depletion in the lower stratosphere is more difficult to explain but might be caused by an exaggerated downward transport of ozone, which could also be an additional reason for the too strong ozone decrease in the upper stratosphere.

On the first forecast day, the ANA runs assimilating all satellite data (see Table 1) with all three model configurations agreed very well with the observed profile in the stratosphere. The maximum error of the monthly mean at any height was about $1 \mathrm{mPa}$, and the maximum deviation of individual profiles was below $2.5 \mathrm{mPa}$. No systematic bias could be found at any level in the stratosphere. The ANA runs were in better agreement with observations than the respective FC runs in all cases. The good agreement could be attributed to the assimilation of MLS data because the NRT forecast with IFSMOZART (IFS-MOZ-ANA*), for which MLS data were not available, produced worse results in particular in September and October. In this period an over-prediction of stratospheric ozone occurred at about $100 \mathrm{hPa}$ which was accompanied by a large under-prediction of tropospheric ozone.

The assimilation had in general a positive impact in the troposphere despite the fact that the lowest MLS partial columns covered only the range from 68 to $214 \mathrm{hPa}$ and that errors larger than $20 \%$ are assigned to this level. It seems that the synergy of column information from SCIAMACHY and OMI being consistent, i.e. bias free, with MLS's stratospheric profile led to improved tropospheric profiles. However, the problem remains, that tropospheric values were not well constrained by the used satellite observations. The model background error specification is likely to strongly influence the tropospheric values of the analyses.

The generally good agreement of the ANA runs with profile observations emphasizes the importance of the assimilation of ozone profile data, such as MLS or MIPAS. Without assimilation of height-resolved data, the vertical structure of the analysis depends entirely on the background error statistics. If the assimilating model does not simulate a realistic profile shape, as in the case of IFS-MOZ-ANA*, the analyzed profiles can deteriorate.

\section{Summary and conclusion}

The paper presents forecast and assimilation experiments of the Antarctic ozone hole from August to December 2008. The focus was put on the impact of three different ways to describe stratospheric ozone chemistry and on the characteristics of satellite observations from MLS, OMI, SCIAMACHY and SBUV-2 in the region of interest. A linearized scheme (IFS), a relaxation to a climatology (IFS-TM5) and a chemistry mechanism including heterogeneous processes on PSCs (IFS-MOZART) were applied as chemistry modules by ECMWF's model and 4D-Var data assimilation system. Ozone-sonde observations were used for the evaluation.

Without correction by ozone analyses, the forecasts differed to a large extent. The linear scheme predicted the chemically instigated ozone depletion too early but produced good results during the more dynamically driven closure of the ozone hole after its peak in September. The climatological scheme captured the development of the ozone hole correctly but did not reproduce the exceptionally long duration of the 2008 event due to the strong forcing towards climatology. The chemical scheme of IFS-MOZART correctly forecast start and duration of the ozone hole, defined as the area with ozone below 220 DU. Its maximum size was underestimated by $20 \%$. The main region of the ozone decrease in the simulations of IFS-MOZART was predominantly the upper and not in the lower stratosphere as observations suggest. A cold bias in the upper stratosphere during winter and exaggerated downward transport of ozone in the polar vortex might be the reasons for this behavior. Nevertheless, the results are an improvement over the simulation of the year 2000 ozone hole with MOZART-3 as presented by Kinnison et al. (2007) because of updates of the model code, in particular improved simulation of surface area density of NAT and ice PSCs, and because of improved meteorological fields. Deficiencies in simulating the amount of ozone depletion by CTMs (e.g. Krämer et al., 2003) and chemistry-climate models (Struthers et al., 2009) have been reported in the literature. More recent studies show improvements in the modeling of surface reactions on PSC which trigger the ozone depletion (e.g. Daerden et al., 2007).

The characteristics of the three different chemistry schemes were overcome by the combined assimilation of MLS, SBUV-2, OMI and SCIAMACHY ozone retrievals. One-day forecasts started from the analyses showed a considerable improvement of bias and error standard deviation when compared with columns and profiles of ozone soundings from seven locations. The analyses made with the different chemistry schemes hardly differed, which showed a dominating impact of the assimilated observations. Only at the time of the development of the ozone hole small differences appeared between the schemes. At this time of the year, the UV-VIS based instruments did not observe a large area south of $60^{\circ} \mathrm{S}$ and MLS was the main information source. 
The overall good agreement of the analyses is different from the finding of an inter-comparison study of linear stratospheric ozone schemes by Geer et al. (2006). They found a more important dependence of the underlying modeling approach on the global scale. However, the assimilation of four independent satellite sensors better constrained the ozone fields than the MIPAS observations used in that paper. The applied observation errors for MIPAS were of similar size $(5 \%)$ as the values used for MLS in this study. Coy et al. (2007) showed improved analyses in the upper stratosphere when using a linear chemical scheme instead of no chemical scheme when assimilating only SBUV-2 observations.

The assimilation of MLS partial column profiles in combination with total column retrievals from OMI and SCIAMACHY proved to be essential for the correctness of the ozone profiles in the stratosphere and the troposphere during the whole period. The importance of the MLS retrievals was demonstrated by comparison with an assimilation run from IFS-MOZART, for which MLS data were not assimilated. This NRT run showed less realistic stratospheric profiles and deteriorated troposphere values, despite good agreement in terms of total columns.

Problems with analyzed ozone profiles from the ERA40 re-analysis have been reported in Dethof and Hólm (2004) and attributed to missing vertical information and biases. By assimilating multiple observations the often complementary information of the sensors, such as high resolution total column observations and vertical profiles, can be gainfully combined. This has been shown in this study and by other authors (Stajner and Wargan, 2004, Jackson, 2007 and Massart et al., 2009). A practical benefit of the multi-sensor approach is that missing or erroneous data will deteriorate the analysis to a smaller extent. The assimilated MLS data covered the stratosphere and a further constraint by total column observations was needed to improve the analyzed ozone fields in the troposphere. Several authors (Stajner et al., 2008; Schoeberl et al., 2007; Ziemke et al., 2006) have used the difference between MLS and OMI to successfully infer tropospheric ozone columns.

The multi-sensor assimilation raises the question of biases among the different sensors. These biases are more difficult to quantify in areas of large gradients because each instrument measures either partial or total columns at different locations and times. The retrievals of the UV instruments are less accurate at low solar elevation. A comparison of the total column values averaged over Antarctica from OMI, SCIAMACHY and partial columns from MLS and SBUV2 showed larger inter-instrument differences only until midOctober, i.e. during the time when the UV-VIS based sensors can only observe ozone at the edges of the Antarctic area. The derived differences among the instruments were therefore mostly related to the sampling and did not constitute biases harmful to the assimilation process. A more detailed study of the biases at the end of August and the end of November confirmed that inter-instrument biases were below 3\%. Both MLS and OMI were nearly bias-free against the analysis while SCIAMACHY showed a higher positive bias at low solar elevation in November. Inter-sensor bias and its quantification is a common problem for data assimilation. Therefore, a variational bias correction scheme (Dee, 2005) will be extended to ozone retrievals assimilated at ECMWF.

This paper investigated the predictability of the ozone hole with respect to the chemical scheme. For this purpose, the ability of the schemes to benefit from an initialization with ozone analyses was studied over a period of 15 days. The importance of the chemistry schemes as such was shown by running forecasts of an initialized tracer without chemical conversion. During the ozone development (1 August-30 September 2008) the bias of this tracer forecast over Antarctica reached about 2.6 DU per forecast day. In the time of the ozone-hole closure (1 October-31 December 2008) the bias was 1 DU per day. The initialized forecasts with IFSMOZART were nearly bias-free during the ozone-hole development. The forecast of a too early start of the ozone hole by the linear scheme could not be corrected by the initialization in mid-August. With the correct initialization, the closure of the ozone hole from October to December was well predicted by the linear scheme, the full scheme of MOZART3 and the tracer over 15 days and longer. The linear scheme had a bias of $0.3 \mathrm{DU}$ and the tracer of $0.8 \mathrm{DU}$ per day, which means that these schemes tended to closed the ozone hole too quickly. The full scheme tended to delay the closure at rate of $-0.8 \mathrm{DU}$ per day. The long-lasting impact of the initialization is proof of the good simulation of the transport processes because the closure of the ozone hole is mainly a dynamically driven process. As expected, the strong relaxation to the climatology in TM5 wiped out the impact of the initialization very quickly, in particular in November and December.

The findings of this paper and others (e.g. Sekiyama and Shibata, 2005) indicate an often long-lasting influence of stratospheric ozone initial conditions in general. Therefore it might become good practice to initialize CTM runs, which are shorter than a year, with analyses. This would not only improve the simulation but could also assist model development because the slow accumulation of biases could be better distinguished from more rapidly developing model deficiencies.

The good forecasts over fifteen days in the Antarctic region by the linear and the full scheme could be used to simulate the radiative impact of ozone in order to improve temperature biases in the ECMWF model (Morcrette, 2003). However, the linear scheme is itself based on climatological temperature and ozone fields, which may limit the applicability of the linear scheme for two-way temperature-ozone feedback studies. It seems more sensitive to forecast temperature biases and would need adjustment for climate-change simulations. A full chemistry scheme could have a bigger potential to correctly simulate these interactions, as shown 
by de Grandpré et al. (2009), even if improvements of the heterogeneous chemistry are still necessary.

Acknowledgements. We thank Rossana Dragani and Martin Suttie for helpful discussions on satellite observation errors. The ozone sonde data used in this publication were obtained as part of the Network for the Detection of Atmospheric Composition Change (NDACC) and the World Ozone and Ultraviolet Radiation Data Centre (WOUDC) and are publicly available from http://www.ndacc.org and http://www.woudc.org. The ozone soundings were carried out by Alfred Wegener Institute-Neumayer (AWI-NM), University of Wyoming, Finnish Meteorological Institute (FMI), National Meteorological Service of Argentina (SNMA), Japan Meteorological Agency (JMA), Australian Bureau of Meteorology (ABM) and National Oceanic and Atmospheric Administration (NOAA). The satellite data were downloaded from the National Aeronautics and Space Administration (NASA), the National Oceanic and Atmospheric Administration (NOAA) and the Koninklijk Nederlands Meteorologisch Instituut (KNMI). The work has been carried out in the GEMS and the MACC project, which are funded by the European Commission under the Sixth and Seventh Research Framework Programme, contract numbers SIP4-CT-2004-516099 and 218793.

Edited by: W. Lahoz

\section{References}

Allaart M. A. F., Kelder H., and Heijboer L. C.: On the relation between ozone and potential vorticity, Geophys. Res. Lett., 20, 811-814, 1993.

Balis, D., Kroon, M. E. Koukouli, E. J. Brinksma, G. Labow, J. P., Veefkind, and McPeters, R. D.: Validation of Ozone Monitoring Instrument total ozone column measurements using Brewer and Dobson spectrophotometer ground-based observations, J. Geophys. Res., 112, D24S46, doi:10.1029/2007JD008796, 2007.

Beekmann M., Ancellet G., Megie G., Smit H. G. J., and Kley D.: Intercomparison campaign for vertical ozone profiles including electrochemical sondes of ECC and Brewer-Mast type and a ground based UV-differential absorption radar, J. Atmos. Chem., 10, 259-288, 1994.

Bhartia, P. K., McPeters, R. D., Mateer C. L., Flynn L. E., and Wellemeyer C.: Algorithm for the estimation of vertical ozone profiles from the backscattered ultraviolet technique, J. Geophys. Res.,101, 18793-18806, 1996.

Benedetti, A., Morcrette, J.-J., Boucher, O., Dethof, A., Engelen, R., Fisher, M., Flentje, H., Huneeus, N., Jones, L., Kaiser, J., Kinne, S., Mangold, A., Razinger, M., Simmons, A., and Suttie, M.: Aerosol analysis and forecast in the European Centre for Medium-Range Weather Forecasts Integrated Forecast System: 2. Data assimilation, J. Geophys. Res., 114, D13205, doi:10.1029/2008JD011115, 2009.

Cariolle, D. and Déqué, M.: Southern hemisphere medium-scale waves and total ozone disturbances in a spectral general circulation model, J. Geophys. Res., 91D, 10825-10846, 1986.

Cariolle, D. and Teyssdre, H.: A revised linear ozone photochemistry parameterization for use in transport and general circulation models: multi-annual simulations, Atmos. Chem. Phys., 7, 2183-2196, doi:10.5194/acp-7-2183-2007, 2007.
Coy, L., Allen, D. R., Eckermann, S. D., McCormack, J. P., Stajner, I., and Hogan, T. F.: Effects of model chemistry and data biases on stratospheric ozone assimilation, Atmos. Chem. Phys., 7, 2917-2935, doi:10.5194/acp-7-2917-2007, 2007.

Daerden, F., Larsen, N., Chabrillat, S., Errera, Q., Bonjean, S., Fonteyn, D., Hoppel, K., and Fromm, M.: A 3D-CTM with detailed online PSC-microphysics: analysis of the Antarctic winter 2003 by comparison with satellite observations, Atmos. Chem. Phys., 7, 1755-1772, doi:10.5194/acp-7-1755-2007, 2007.

Dee, D. P.: Bias and data assimilations, Q. J. Roy. Meteorol. Soc., 131, 3323-3343, 2005.

de Laat, A. T. J., van der A, R. J., and van Weele, M.: Evaluation of tropospheric ozone columns derived from assimilated GOME ozone profile observations, Atmos. Chem. Phys., 9, 8105-8120, doi:10.5194/acp-9-8105-2009, 2009.

de Grandpré, J., Ménard, R., Rochon, Y. J., Charrette, C., Chabrillat, S., and Robichaud, A.: Predictability of coupled chemistrydynamics data assimilation, Mon. Weather Rev., 137(25), 679692, 2009.

Derber, J. C. and Wu, W.-S.: The Use of TOVS Cloud-Cleared Radiances in the NCEP SSI Analysis System, Mon. Weather Rev., 126, 2287-2299, 1998.

Dethof, A. and Hólm, E. V.: Ozone assimilation in the ERA-40 reanalysis project, Q. J. Roy. Meteorol. Soc.,130, 2851-2872, 2004.

Dragani, R.: Monitoring and assimilation of SCIAMACHY, GOMOS and MIPAS retrievals at ECMWF. Annual Report for ESA contract 21519/08/I-OL: Technical support for global validation of ENVISAT data products, available online at: http://www. ecmwf.int/publications/library/do/references/list/18, 2009.

Errera, Q., Daerden, F., Chabrillat, S., Lambert, J. C., Lahoz, W. A., Viscardy, S., Bonjean, S., and Fonteyn, D.: 4D-Var assimilation of MIPAS chemical observations: ozone and nitrogen dioxide analyses, Atmos. Chem. Phys., 8, 6169-6187, doi:10.5194/acp8-6365-2008, 2008.

Eskes, H. J., van Velthoven, P., and Kelder, H.: Global ozone forecasting based on ERS-2 GOME observations, Atmos. Chem. Phys., 2, 271-278, doi:10.5194/acp-2-271-2002, 2002.

Eskes, H. J., van Velthoven, P. F. J., Valks, P. J. M., and Kelder, H. M.: Assimilation of GOME total ozone satellite observations in a three-dimensional tracer transport model, Q. J. Roy. Meteorol. Soc., 129, 1663, doi:10.1256/qj.02.14, 2003.

Eskes, H. J., van der A, R. J., Brinksma, E. J., Veefkind, J. P., de Haan, J. F., and Valks, P. J. M.: Retrieval and validation of ozone columns derived from measurements of SCIAMACHY on Envisat, Atmos. Chem. Phys. Discuss., 5, 44294475, doi:10.5194/acpd-5-4429-2005, 2005.

Fisher, M. and Andersson, E.: Developments in 4D-Var and Kalman Filtering. ECMWF Technical Memorandum 347, ECMWF, Shinfield Park, Reading, Berkshire, RG2 9AX, UK, 2001.

Fisher, M.: Wavelet Jb - A new way to model the statistics of background errors. ECMWF Newsletter, 106, 23-28, ECMWF, Shinfield Park, Reading, Berkshire, RG2 9AX, UK, 2006.

Flemming, J., Inness, A., Flentje, H., Huijnen, V., Moinat, P., Schultz, M. G., and Stein, O.: Coupling global chemistry transport models to ECMWF's integrated forecast system, Geosci. Model Dev., 2, 253-265, doi:10.5194/acp-2-253-2009, 2009.

Fortuin, J. P. F. and Kelder, H.: An ozone climatology based on ozonesonde and satellite measurements, J. Geophys. Res., 103, 
31709-31734, 1998.

Froidevaux, L., Jiang, Y. B., Lambert, A., Livesey, N. J., Read, W. G., Waters, J. W., Browell, E. V., Hair, J. W., Avery, M. A., McGee, T. J., Twigg, L.W., Sumnicht, G. K., Jucks, K. W., Margitan, J. J., Sen, B., Stachnik, R. A., Toon, G. C., Bernath, P. F., Boone, C. D., Walker, K. A., Filipiak, M. J., Harwood, R. S., Fuller, R. A., Manney, G. L., Schwartz, M. J., Daffer, W. H., Drouin, B. J., Cofield, R. E., Cuddy, D. T., Jarnot, R. F., Knosp, B.W., Perun, V. S., Snyder, W. V., Stek, P. C., Thurstans, R. P., and Wagner, P. A.: Validation of Aura Microwave Limb Sounder stratospheric ozone measurements, J. Geophys. Res., 113, D15S20, doi:10.1029/2007JD008771, 2008.

Geer, A. J., Lahoz, W. A., Bekki, S., Bormann, N., Errera, Q., Eskes, H. J., Fonteyn, D., Jackson, D. R., Juckes, M. N., Massart, S., Peuch, V.-H., Rharmili, S., and Segers, A.: The ASSET intercomparison of ozone analyses: method and first results, Atmos. Chem. Phys., 6, 5445-5474, doi:10.5194/acp-6-5445-2006, 2006.

Geer, A. J., Lahoz, W. A., Jackson, D. R., Cariolle, D., and McCormack, J. P.: Evaluation of linear ozone photochemistry parametrizations in a stratosphere-troposphere data assimilation system, Atmos. Chem. Phys., 7, 939-959, doi:10.5194/acp-7939-2007, 2007.

Gray, L. J. and Pyle, J. A.: A two dimensional model of the quasibiennial oscillation of ozone, J. Atmos. Sci., 46, 203-220, 1989.

Hollingsworth, A., Engelen, R. J., Textor, C., Benedetti, A., Boucher, O., Chevallier, F., Dethof, A., Elbern, H., Eskes, H., Flemming, J., Granier, C., Kaiser, J. W., Morcrette, J.-J., Rayner, P., Peuch, V. H., Rouil, L., Schultz, M. G., Simmons, A. J., and The GEMS Consortium: Towards a Monitoring and Forecasting System For Atmospheric Composition: The GEMS Project, Bull. Am. Meteorol. Soc., 89, 1147-1164, 2008.

Hólm, E. V., Untch, A., Simmons, A., Saunders, R., Bouttier, F., and Andersson, E.: Multivariate ozone assimilation in fourdimensional data assimilation, in: Proceedings of the SODAWorkshop on Chemical Data Assimilation, 9-10 December 1998, KNMI, De Bilt, The Netherlands, 89-94, 1999.

Horowitz, L. W., Walters, S., Mauzerall, D. L., Emmons, L. K., Rasch, P. J., Granier, C., Tie, X. X., Lamarque, J. F., Schultz, M. G., Tyndall, G. S., Orlando, J. J., and Brasseur, G. P.: A global simulation of tropospheric ozone and related tracers: Description and evaluation of MOZART, version 2, J. Geophys. Res., 108(D24), 4784, doi:10.1029/2002JD002853, 2003.

Hortal, M. and Simmons, A. J.: Use of reduced Gaussian grids in spectral models, Mon. Weather Rev., 119, 1057-1074, 1991.

Houweling, S., Dentener, F., and Lelieveld, J.: The impact of non-methane hydrocarbon compounds on tropospheric photochemistry, J. Geophys. Res., 103(D9), 10673-10696, doi:10.1029/97JD03582, 1998.

Inness, A., Flemming, J., Suttie, M., and Jones, L.: GEMS data assimilation system for chemically reactive gases, Technical Memoradum No. 587, European Centre for Medium-Range Weather Forecasts (ECMWF), 2009.

Jackson, D. R: Assimilation of EOS MLS ozone observations in the Met Office data-assimilation system, Q. J. Roy. Meteorol. Soc., 133, 1771-1788, 2007.

Jackson, D.R., and Orsolini, Y.J.: Estimation of Arctic ozone loss in winter 2004/05 based on assimilation of EOS MLS observations, Q. J. Roy. Meteorol. Soc., 134, 1833-1841, 2008.
Josse, B., Simon, P., and Peuch, V.-H.: Rn-222 global simulations with the multiscale CTM MOCAGE, Tellus, 56B, 339-356, 2004.

Kalnay, E. : Atmospheric Modeling, Data Assimilation and Predictability, Cambridge University Press, Cambridge, 341 pp., 2003.

Kinnison, D. E., Brasseur, G. P., Walters, S., Garcia, R. R., Marsh, D. R , Sassi, F., Harvey, V. L., Randall, C. E., Emmons, L., Lamarque, J. F., Hess, P., Orlando, J. J., Tie, X. X., Randel, W., Pan, L. L., Gettelman, A., Granier, C., Diehl, T., Niemeier, U., and Simmons, A. J.: Sensitivity of Chemical Tracers to Meteorological Parameters in the MOZART3 Chemical Transport Model, J. Geophys. Res, 112, D03303, doi:10.1029/2008JD010739, 2007.

Khattatov, B. V., Lamarque, J.-F., Lyjak, L. V., Ménard, R., Levelt, P. F., Tie, X. X., Gille, C., and Brasseur, G. P.: Assimilation of satellite observations of long-lived chemical species in global chemistry-transport models, J. Geophys. Res., 105, 29135-29144, 2000.

Krämer, M., Müller, R., Bovensmann, H., Burrows, J., Brinkmann, J., Röth, E.P., Grooß, J.-U., Müller, R., Woyke, T., Ruhnke, R., Günther, G., Hendricks, J., Lippert, E., Carslaw, K. S., Peter, T., Zieger, A., Brühl, C., Steil, B., Lehmann, R., and McKenna, D. S.: Intercomparison of Stratospheric Chemistry Models under Polar Vortex Conditions, J. Atmos. Chem., 45, 51-77, 2003.

Krol, M.C., Houweling, S., Bregman, B., van den Broek, M., Segers, A., van Velthoven, P., Peters, W., Dentener F. and Bergamaschi, P.: The two-way nested global chemistry-transport zoom model TM5: algorithm and applications Atmos. Chem. Phys., 5, 417-432, doi:10.5194/acp-5-417-2005, 2005.

Lahoz, W. A., Errera, Q., Swinbank, R., and Fonteyn, D.: Data assimilation of stratospheric constituents: a review, Atmos. Chem. Phys., 7, 5745-5773, doi:10.5194/acp-7-5745-2007, 2007.

Levelt, P. F., Khattatov, B. V., Gille, J. C., Brasseur, G. P., Tie, X. X. and Waters, J.W.: Assimilation of MLS ozone measurements in the global three-dimensional chemistry transport model ROSE, Geophys. Res. Lett., 25, 4493-4496, 1998.

Long, C. S., Miller, A. J., Lee, H. T., Wild, J. D., Przywarty, R. C., and Hufford, D.: Ultraviolet Index Forecasts issued by the National Weather Service, Bull. Amer. Meteorol. Soc., 77, 729748, 1996.

Lorenz, E.: Predictability - a problem nearly solved, in Predictability of Weather and Climate, edited by: Palmer, T. and Hagedorn, R., Cambridge University Press, Cambridge, 2006.

Mahfouf, J. F. and Rabier, F.: The ECMWF operational implementation of four-dimensional variational assimilation. Part I: experimental results with improved physics, Q. J. Roy. Meteorol. Soc. 126, 1171-1190, 2000.

Massart, S., Clerbaux, C., Cariolle, D., Piacentini, A., Turquety, S., and Hadji-Lazaro, J.: First steps towards the assimilation of IASI ozone data into the MOCAGE-PALM system, Atmos. Chem. Phys., 9, 5073-5091, doi:10.5194/acp-9-5073-2009, 2009.

McCormack, J. P., Eckermann, S. D., Siskind, D. E., and McGee, T. J.: CHEM2D-OPP: A new linearized gas-phase ozone photochemistry parameterization for high-altitude NWP and climate models, Atmos. Chem. Phys., 6, 4943-4972, doi:10.5194/acp-64943-2006, 2006.

McLinden, C. A., Olsen, S. C., Hannegan, B., Wild, O., Prather, M. J., and Sundet, J.: Stratospheric ozone in 3-D models: A sim- 
ple chemistry and the cross-tropopause flux, J. Geophys. Res., 105(D11), 14653-14665, 2000.

Ménard, R., Cohn, M., Chang, L. P., and Lyster, P. M.: Assimilation of Stratospheric Chemical Tracer Observations Using a Kalman Filter. Part I: Formulation, Mon. Weather Rev., 128, 2654-2671, 2000.

Monge-Sanz, B. M., Chipperfield, M. P., Simmons, A. J., and Uppala, S. M.: Mean age of air and transport in a CTM: Comparison of different ECMWF analyses, Geophys. Res. Lett., 34, L04801, doi:10.1029/2006GL028515, 2007.

Morcrette, J.-J.: Ozone-radiation interactions in the ECMWF forecast system. Technical Memoradum No. 375, European Centre for Medium-Range Weather Forecasts (ECMWF), 2003.

Newman, P. A., Kawa, S. R., and Nash, E. R.: On the size of the Antarctic ozone hole, Geophys. Res. Lett., 31, L21104, doi:10.1029/2004GL020596, 2004.

Newman P. A., Nash, E. R., Kawa, N. R., Montzka, S. A., and Schauffler, S. M.: When will the Antarctic ozone hole recover?, Geophys. Res. Lett., 33, L12814, doi:10.1029/2005GL025232, 2006.

Palmer, T. and Hagedorn, R. (Eds.): Predictability of Weather and Climate, Cambridge University Press, Cambridge, 718 pp., 2006.

Riishojgaard, L. P.: On four-dimensional variational assimilation of ozone data in weather prediction models, Q. J. Roy. Meteorol. Soc., 122, 1545-1571, 1996.

Rind, D., Lerner, J., Jonas, J., and McLinden, C.: Effects of resolution and model physics on tracer transports in the NASA Goddard Institute for Space Studies general circulation models, J. Geophys. Res., 112, D09315, doi:10.1029/2006JD007476, 2007.

Sander, S. P., Friedl, R. R., Golden, D. M., Kurylo, M. J., Moortgat, G. K., Keller-Rudek, H., Wine, P. H., Ravishankara, A. R., Kolb, C. E., Molina, M. J., Finlayson-Pitts, B. J., Huie, R. E., and Orkin, V. L.: Chemical Kinetics and Photochemical Data for Use in Atmospheric Studies, Evaluation Number 15, JPL Publication 06-02, Jet Propulsion Laboratory, Pasadena, Calif., USA, 2006.

Schoeberl, M. R., Ziemke, J. R., Bojkov, B., Livesey, N., Duncan, B., Strahan, S., Froidevaux, L., Kulawik, S., Bhartia, P. K., Chandra, S., Levelt, P. F., Witte, J. C., Thompson, A. M., Cuevas, E., Redondas, A., Tarasick, D. W., Davies, J., Bodeker, G., Hansen, G., Johnson, B. J., Oltmans, S. J., Vömel, H., Allaart, M., Kelder, H., Newchurch, M., Godin-Beekmann, S., Ancellet, G., Claude, H., Andersen, S. B., Kyrö, E., Parrondos, M., Yela, M., Zablocki, G., Moore, D., Dier, H., von der Gathen, P., Viatte, P., Stbi, R., Calpini, B., Skrivankova, P., Dorokhov, V., de Backer, H., Schmidlin, F. J., Coetzee, G., Fujiwara, M., Thouret, V., Posny, F., Morris, G., Merrill, J., Leong, C. P., Koenig-Langlo, G., and Joseph, E.: A trajectory-based estimate of the tropospheric ozone column using the residual method, J. Geophys. Res., 112, D24S49, doi:10.1029/2007JD008773, 2007.

Sekiyama T. T. and Shibata, K.: Predictability of total ozone using a global three-dimensional chemical transport model coupled with the MRI/JMA98 GCM, Mon. Weather Rev., 133(8), 2262-2274, 2005.

Simmons, A., Hortal, M., Kelly, G., McNally, T., Untch, A., and Uppala, S.: ECMWF Analyses and Forecasts of Stratospheric Winter Polar Vortex Breakup: September 2002 in the Southern Hemisphere and Related Events, J. Atmos. Sci., 62, 668-689, 2005.

Solomon, S.: Stratospheric ozone depletion: a review, Rev. of Geo- phys., 37, 275-316, 1999.

SPARC CCMVal, SPARC Report on the Evaluation of ChemistryClimate Models, edited by: Eyring, V., Shepherd, T. G., Waugh, D. W., SPARC Report No. 5, WCRP-132, WMO/TD-No. 1526, online available at: http://www.atmosp.physics.utoronto. ca/SPARC, 2010.

Stajner, I. and Wargan, K.: Antarctic stratospheric ozone from the assimilation of occultation data, Geophys. Res. Lett, 31, L18108, doi:10.1029/2004GL020846, 2004.

Stajner, I., Wargan, K. , Chang, L.-P., Hayashi, H. , Pawson, S. and Nakajima, H. : Assimilation of ozone profiles from the Improved Limb Atmospheric Spectrometer-II: study of Antarctic ozone, J. Geophys. Res., 111, D11S14, doi:10.1029/2005JD006448, 2006.

Stajner, I., Wargan, K., Pawson, S., Hayashi, H., Chang, L., Hudman, R. C., Froidevaux, L., Livesey, N., Levelt, P. F., Thompson, A. M., Tarasick, D. W., Stübi, R., and Andersen, S. B.: Assimilated ozone from EOS-Aura: Evaluation of the tropopause region and tropospheric columns, J. Geophys. Res., 113, D16S32, doi:10.1029/2007JD008863, 2008.

Struthers, H., Bodeker, G. E., Austin, J., Bekki, S., Cionni, I., Dameris, M., Giorgetta, M. A., Grewe, V., Lefèvre, F., Lott, F., Manzini, E., Peter, T., Rozanov, E., and Schraner, M.: The simulation of the Antarctic ozone hole by chemistry-climate models, Atmos. Chem. Phys., 9, 6363-6376, doi:10.5194/acp-9-63632009, 2009.

Tegtmeier, S. and Shepherd, T. G.: Persistence and photochemical decay of springtime total ozone anomalies in the Canadian Middle Atmosphere Model, Atmos. Chem. Phys., 7, 485-493, doi:10.5194/acp-7-485-2007, 2007.

van der Werf, G. R., Randerson, J. T., Giglio, L., Collatz, G. J., and Kasibhatla, P. S.: Interannual variability in global biomass burning emission from 1997 to 2004. Atmos. Chem. Phys., 6, 3423-3441, doi:10.5194/acp-6-3423-2006, 2006.

van Noije, T. P. C., Eskes, H. J., van Weele, M., and van Velthoven, P. F. J.: Implications of the enhanced Brewer-Dobson circulation in European Centre for Medium-Range Weather Forecasts reanalysis ERA-40 for the stratosphere-troposphere exchange of ozone in global chemistry transport models, J. Geophys. Res., 2004, 109, D19308, doi:10.1029/2004JD004586, 2004.

van Peet, J. C. A., van $\operatorname{der}$ A, R. J., de Laat, A. T. J., Tuinder, O. N. E., König-Langlo, G., and Wittig, J.: Height resolved ozone hole structure as observed by the Global Ozone Monitoring Experiment-2, Geophys. Res. Lett., 36, L11816, doi:10.1029/2009GL038603, 2009.

WMO: Antarctic ozone Bulletin, No 3/2008, available online at: http://www.wmo.int/pages/prog/arep/gaw/ozone/index.html, 2008.

WMO/UNEP: Scientific Assessment of Ozone Depletion: 2006, Global Ozone and onitoring Project, Report No. 50, 572 pp., Geneva, Switzerland, available online at: http://www.wmo.int/ pages/prog/arep/gaw/ozone/index, 2007.

Ziemke, J. R., Chandra, S., Duncan, B. N., Froidevaux, L., Bhartia, P. K., Levelt, P. F., and Waters, J. W.: Tropospheric ozone determined from Aura OMI and MLS: Evaluation of measurements and comparison with the Global Modeling Initiative's Chemical Transport Model, J. Geophys. Res., 111, D19303, doi:10.1029/2006JD007089, 2006. 